\title{
Feature economy in sound systems
}

\author{
G. N. Clements
}

CNRS/Sorbonne-Nouvelle, Paris

Reprint from Phonology 20 (2003), 287-333

Copyright 2003 Cambridge University Press

DOI: $10.1017 /$ S095267570400003X

link: http://journals.cambridge.org/action/displayJournal?jid=PHO 


\title{
Feature economy in
}

\section{sound systems $*$}

\author{
G. N. Clements \\ CNRS/Sorbonne-Nouvelle, Paris
}

\begin{abstract}
Feature economy is a principle of sound systems according to which languages tend to maximise the ratio of sounds over features. The major goal of this study is to confirm the predictions of feature economy at the synchronic level, using an objective sampling technique applied to a genetically and areally balanced sample of the world's languages. It also shows that feature economy can be used as a tool in phonological feature analysis, and offers voiced aspirates, voiceless sonorants and various types of glottalised sounds as illustrations. Feature economy applies not only to distinctive feature values, but to redundant values of features that are distinctive or phonologically active elsewhere in the system. Feature economy cannot be reduced to a purely phonetic principle of gesture economy, but may reflect a general principle of linguistic organisation according to which the active categories of a grammatical system tend to be used to maximal effect.
\end{abstract}

\section{Introduction}

\subsection{Feature economy}

Speech sounds tend to occur in series, such as 'voiced fricatives' or 'front rounded vowels'; but why? This study argues that FEATURE ECONOMY is a basic organisational principle of sound systems. According to this principle, languages tend to maximise the combinatory possibilities of features across the inventory of speech sounds: features used once in a system tend to be used again. The major goal of this study is to test the

* The UPSID-92 database has been an invaluable resource in carrying out this work, and I would like to thank its creator, Ian Maddieson, for helping me with questions at various times. Thanks are also due to Hannah Rohde for assistance in developing computational tools, to Jean-Yves Dommergues for advice on statistical modelling, and to Maarten Mous, Paul Newman, David Odden and Tony Traill for answering questions on language data. I have benefited from comments by Caroline Féry, Andrea Calabrese and a further anonymous reader. Finally I would like to thank participants at the following meetings, especially Elsa Gomez, Gregory Guy, Elizabeth Hume, Jeff Mielke and Curt Rice, for stimulating discussion: the 3e Journées d'études linguistiques 'Les universaux sonores' (Nantes, 2002), the 4e Journées Internationales du GDR 'Phonologie' (Grenoble, 2002), the 2nd International Phonology Seminar (Porto Alegre, 2002), the 1st Old World Conference on Phonology (OCP 1; Leiden, 2003), the LSA Linguistic Institute (East Lansing, 2003) and the 15th International Conference of Phonetic Sciences (Barcelona, 2003). 
predictions of feature economy at the synchronic level, using an objective sampling technique applied to a genetically and areally balanced sample of the world's languages. A further goal is to show that feature economy can be used as a criterion to discriminate between competing feature analyses.

As an illustration of feature economy, let us examine the three consonant systems in (1):

(1) Three consonant systems

a. Hawaiian: 8 consonants (after Elbert \& Pukui 1979)

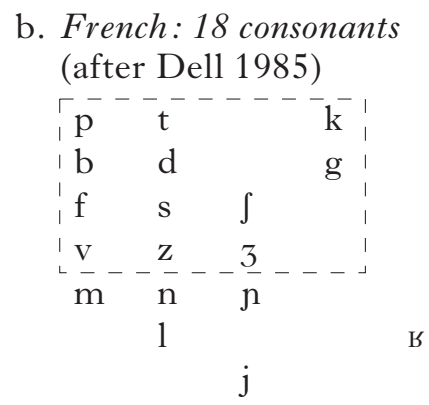

c. Nepali: 27 consonants (after Bandhu et al. 1971)

$\left[\begin{array}{lllll}\mathrm{p} & \mathrm{t} & \mathrm{ts} & \mathrm{t} & \mathrm{k} \\ \mathrm{p}^{\mathrm{h}} & \mathrm{t}^{\mathrm{h}} & \mathrm{ts} & \mathrm{t}^{\mathrm{h}} & \mathrm{k}^{\mathrm{h}} \\ \mathrm{b} & \mathrm{d} & \mathrm{dz} & \mathrm{d} & \mathrm{g} \\ \mathrm{b}^{\mathrm{h}} & \mathrm{d}^{\mathrm{h}} & \mathrm{dz} & \mathrm{d}^{\mathrm{h}} & \mathrm{g}^{\mathrm{h}}\end{array}\right.$

m n

$1, \mathrm{r}$

These systems vary greatly in size and content. Yet each displays feature economy to varying degrees, as is shown by the sounds enclosed in the boxes. In Hawaiian, three manners of articulation (stop, nasal, approximant) cross-classify two basic places of articulation (labial vs. non-labial) to give six supralaryngeal consonants, the theoretical maximum that can be obtained with these categories $(2 \times 3)$. In French, voicing is fully exploited in stops and fricatives to double the number of obstruents $(6 \times 2)$. Nepali uses five places of articulation and four manners of articulation within its stop system to obtain twenty stops $(5 \times 4)$, with no gaps. Examples such as these are typical, and similar examples can be found in most other languages.

It is also typical, however, that not all theoretical feature combinations are realised. For example, Hawaiian has no nasalised $h$, French avoids palatal stops and velar fricatives and Nepali balks at voiceless or aspirated nasals, even though further economy could be achieved by allowing them. In many such cases, avoided feature combinations can be shown to be 
inefficient from the point of view of speech communication. That is, their articulation is relatively complex, or their auditory attributes are not distinct enough from those of some other sound in the system. For example, the difference between an oral and nasal $h$ is auditorily subtle, palatal stops require an active retraction of the tongue-blade articulator, and voiceless $[\mathrm{n}]$ and $[\mathrm{m}]$ are hard to distinguish from each other and from [h], etc. While we therefore find exceptions to feature economy, such exceptions normally correspond to functionally inefficient feature combinations which tend to be avoided across languages.

It is possible to give a quantitative measure of feature economy. One way of doing this is in terms of a measure called the ECONOMY INDEX. This is simply the ratio of speech sounds in a system over the smallest number of features required to characterise them. Thus, given a system with $S$ speech sounds characterised by $F$ features, its economy index, $E$, is given by expression (2):

(2) $\mathrm{E}=\mathrm{S} / \mathrm{F}$

The higher the value of $E$, the greater the economy.

Feature economy can be defined quite simply as the tendency to maximise $E$. This can be achieved either by increasing $S$ or by decreasing $F$. In other words, we can obtain an increase in economy either by increasing the number of speech sounds in the system or by decreasing the number of features. For example, the economy of the French system could be increased either by adding the sounds $[\mathrm{t}],\left[\mathrm{d}_{5}\right]$ or $[\mathrm{g}]$, all of which are characterised by already existing features, or by replacing the postalveolar sounds $\left[\int_{3} \mathrm{n}\right]$ with the corresponding velar sounds, eliminating the distinctive feature underlying palatality.

Let us see how this measure can be applied to the systems shown in (1). (3) contains all and only the features required to distinguish all consonants in each system, following an algorithm described in Clements (2001). Checks correspond to distinctive features and blanks to nondistinctive features. For example, [voiced] is left unchecked for Hawaiian, in which this feature is non-distinctive, but it is present for French and Nepali, in which it distinguishes pairs of consonants like $/ \mathrm{p} /$ and $/ \mathrm{b} /{ }^{1}$

1 The features [posterior] and [laminal] are used here and below in the same role as the traditional features [anterior] and [distributed]. The feature [coronal] is not present in the table since [labial], [dorsal] and [+ posterior] are sufficient to distinguish all oral places of articulation in these languages. Note that neither [coronal] nor [dorsal] is distinctive in Hawaiian, as non-labial stops are predictably dorsal and non-labial nasals predictably coronal. 
(3) Distinctive features in Hawaiian, French and Nepali consonants

[sonorant]
[labial]
[dorsal]
[nasal]
[voice]
[spread glottis]
[constricted glottis]
[continuant]
[posterior]
[apical]
[lateral]
total

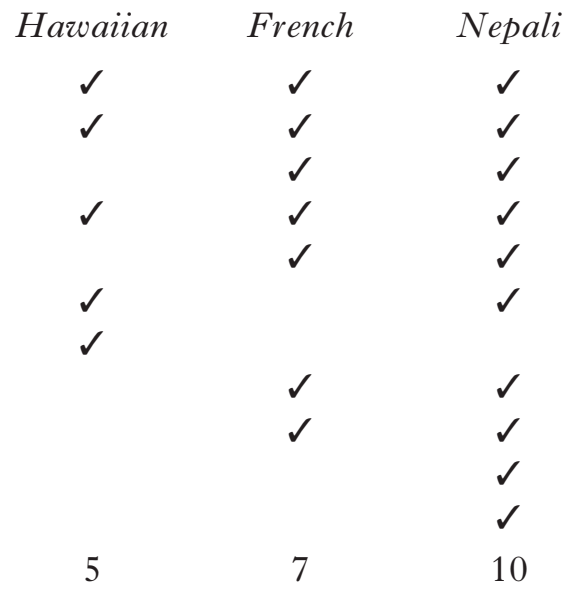

Given these features, we obtain the ranking shown in Table I:

$\begin{array}{lccc} & \text { distinctive features } & \text { consonants } & \text { economy index } \\ \text { Hawaiian } & 5 & 8 & 1 \cdot 60 \\ \text { French } & 7 & 18 & 2 \cdot 57 \\ \text { Nepali } & 10 & 27 & 2 \cdot 70\end{array}$

Table I

Economy of the Hawaiian, French and Nepali systems compared (economy index $=S / F)$.

All systems show some degree of economy. However, of these systems, Hawaiian is the least economical and Nepali the most.

Interestingly, none of these languages comes anywhere close to attaining the theoretical maximum of $2^{\mathrm{n}}$ sounds for a system of $n$ features. This observation illustrates the force of the constraints that disfavour or exclude dysfunctional feature combinations. In this respect, too, these three languages are quite typical.

\subsection{Feature economy is not parsimony}

It is important to distinguish economy in the above sense from its nearsynonym PARSIMONY, since the two terms are sometimes used interchangeably (e.g. by Hockett 1955: 159-160). Parsimony is a principle which favours small inventories over large ones, all else being equal. Viewed as an analytical criterion (an instance of Occam's Razor), it tells the linguist not to multiply entities beyond necessity. This is of course good scientific practice, and applies to all aspects of theory construction. Viewed as a 
constraint on system size, however, it is more dubious. Under this interpretation, speakers would be expected to prefer small inventories to large ones, all else being equal; but in this sense, the principle has never been very seriously maintained. Taken literally, it would predict that languages should prefer Hawaiian-type systems, while in fact, Hawaiian, with its eight consonants, is an atypically low-inventory system (Maddieson 1984). It would also predict that language evolution should lead to massive phoneme mergers, triggered solely by pressure to reduce the inventory, which is also contrary to observation: most phoneme mergers result from articulatory, perceptual and functional considerations, such as the pressure to eliminate marginal, non-salient contrasts. ${ }^{2}$

Unlike parsimony, feature economy does not require phoneme sets to be small. Instead it favours maximising the number of phonemes that can be obtained by the free combination of a given set of features. Nor does it require feature sets to be small; it states that whatever their size, they should be used efficiently. To see the difference between these two notions, we can compare the consonant systems of Hawaiian, French and Nepali in terms of economy and parsimony. As we see from the first two columns in Table I, Hawaiian is the most parsimonious of these systems and Nepali the least parsimonious, whether we count speech sounds or features. In contrast, as the third column shows, Nepali has the most economical system and Hawaiian the least. Thus in these systems, economy is inversely related to parsimony.

\subsection{Feature economy is not symmetry}

Feature economy is also different from the notion of SYMMETRY (or the related concept of PATTERN CONGRUITY) which is sometimes invoked in the earlier literature (e.g. Hockett 1955: 140-142, 158-159, Chomsky \& Halle 1968: 410, 414). This criterion favours analyses that yield the greatest symmetry. For example, the set of four consonants [ $\mathrm{tkdg}$ ] is favoured over systems lacking any one of its members, since [t] is to [k] as [d] is to $[\mathrm{g}]$ (Hockett 1955:140).

This principle may sometimes have heuristic value in leading the analyst to useful hypotheses. When unconstrained by feature analysis, however, it reduces to the subjective exercise of lining up phonemes on the page. (For instance, the 'symmetry' of the French consonant system could be increased by putting postalveolar consonants and velar consonants in the same column in (1), in spite of their different place features.) This practice can lead to highly abstract and arbitrary analyses, and for this reason it is seldom appealed to in current phonological theory. Its core insight, that languages disfavour 'gaps', can be shown to follow as a consequence of feature economy (see below).

To see the difference between symmetry and feature economy, let us consider the hypothetical systems in (4).

${ }^{2}$ For further critique of the notion of parsimony see Hockett (1955 : 159-160). 
(4) Three sound systems differing in symmetry and economy

$\begin{array}{cccc}\text { system } & A \\ \mathrm{p} & \mathrm{t} & \mathrm{c} & \mathrm{k} \\ \mathrm{b} & \mathrm{d} & \mathrm{J} & \mathrm{g} \\ \mathrm{f} & \mathrm{s} & \int & \mathrm{x} \\ \mathrm{v} & \mathrm{z} & 3 & \mathrm{v}\end{array}$

system $B$

$\begin{array}{llll}\mathrm{p} & \mathrm{t} & \mathrm{c} & \mathrm{k} \\ \mathrm{b} & \mathrm{d} & \mathrm{J} & \mathrm{g} \\ \mathrm{f} & \mathrm{s} & \mathrm{f} & \mathrm{x}\end{array}$

\begin{tabular}{llll}
\multicolumn{5}{c}{ system } & & \\
$\mathrm{p}$ & $\mathrm{t}$ & $\mathrm{c}$ & $\mathrm{k}$ \\
$\mathrm{b}$ & $\mathrm{d}$ & $\mathrm{f}$ & $\mathrm{g}$ \\
$\mathrm{f}$ & $\mathrm{s}$ & & $\mathrm{x}$ \\
$\mathrm{v}$ & & 3 &
\end{tabular}

System $A$ is symmetrical and fully economical $(E=16 / 5=3 \cdot 20)$; the manner features [continuant] and [voiced] are used to maximum effect across all four places of articulation. ${ }^{3}$ System $B$ is also symmetrical, but it is not fully economical, as [voiced] does not combine with [continuant] $(E=12 / 5=2 \cdot 40)$. System $C$ is more economical than $B$ since it obtains more phonemes with the same features $(E=13 / 5=2 \cdot 60)$, but it is not fully symmetrical due to the gaps. Thus full symmetry does not necessarily imply full economy (system $B$ ), nor does an increase in economy necessarily imply an increase in symmetry (system $C$ vs. system $B$ ). The two concepts are quite different.

\subsection{Feature economy is not representational economy}

Feature economy is also related to the notion of REPRESENTATIONAL ECONOMY, which maintains that features are present in phonological representations only if they are lexically distinctive or phonologically active (Clements 2001). Representational economy does not strictly imply feature economy, since it is applicable to economical and uneconomical sound systems alike. It nevertheless bears on feature economy in that only features that are actually present in representations can be expected to exert economy effects. If representations predominantly contain only marked values of distinctive features, for example, only such values should show economy effects. We shall review the evidence for such a preference in the concluding discussion $(\$ 7)$.

\subsection{Historical sources and current status of feature economy}

Feature economy seems to have been introduced by the Dutch linguist A. W. de Groot. His paper 'Phonologie und Phonetik als Funktionswissenschaften', read at the 1st International Phonology Meeting in Prague in 1930, was the first to lay out the basic principles of functionalist phonology which were subsequently developed by Martinet and others. Regarding feature economy, de Groot wrote (1931: 121): ${ }^{4}$

Eine zweite Hypothese ist diese, daß versucht wird, gewisse mitcharakterisierende Phonemeigenschaften mehr als einmal $\mathrm{zu}$ verwenden: man könnte hier von einer Tendenz zur Ökonomie reden. [A second

3 In this paper the term 'manner feature' is used for convenience to refer to all features other than place features. No 'manner node' is implied.

4 Translations here and below are the author's. 
hypothesis is that there is a tendency to employ certain accompanying phoneme properties more than once; one can speak here of a tendency toward economy.]

By way of illustration, de Groot observed that consonant systems often make repeated use of such properties as occlusion and frication, labiality, dentality and velarity, nasality and orality, and voicing and voicelessness. In later work he characterised feature economy as a principle underlying sound change (de Groot 1948: 192):

We may further take it as a general rule that, ceteris paribus, those phonemes appear first and most easily which have only phoneme marks already figuring in the phoneme system.

De Groot was inspired by the observation, which he attributed to van Wijk, that new phonemes often enter a system in 'open spaces', or gaps, as we would now say. By defining gaps in terms of marks (i.e. as missing feature combinations), he was able to give a more precise characterisation of this principle.

Feature economy was further developed by Martinet in Chapter 4 ('Économie') of his Économie des changements phonétiques (1955), whose main points are summarised for English-speaking readers in Martinet (1968: 480-485). After describing the initial economy achieved by representing the meaningful units of a language in terms of phonemes, Martinet wrote (1955: 95):

Une nouvelle économie est réalisée en faisant résulter [les phonèmes] de combinaisons de traits phoniques non-successifs, ce qui réduit encore le nombre des éléments de base. [Further economy is achieved by making [phonemes] result from combinations of non-successive phonic features, which further reduces the number of basic elements.]

A feature-based phoneme system is thus more economical than one in which each phoneme involves an entirely unique articulation. But Martinet stressed that features do not always combine freely; he continues:

Il ne s'agit pas de n'importe quelles combinaisons, mais seulement de celles qui par leur nature servent au mieux les besoins de la communication. [It's not a matter of just any combinations, but only those that by their nature best serve the needs of communication.]

Feature economy is thus constrained by functional considerations imposed by the nature of speech communication, favouring sounds that are easy to articulate and easy to perceive. Other functional considerations include the need to maintain a minimum 'margin of security' between auditorily similar phonemes so that they do not become confused. This means that a potential feature combination will be disfavoured if the resulting sound cannot be easily distinguished from another sound in the system. 
Martinet proposed several possible motivations for feature economy (1968: 483): (i) for the same total of phonemes, they require fewer articulations to keep distinct; (ii) these articulations, being less numerous, will be more distinct; (iii) each of them being more frequent in speech, speakers will have more occasions to perceive and produce them, and they will get anchored sooner in the speech of children.

In later work, especially in the United States, the notion of feature economy came to be confused with notions of parsimony, symmetry and pattern congruity as discussed above. Even today, these notions are often not clearly distinguished. Nevertheless, feature economy (and closely related ideas) continue to appear in the theoretical literature, though usually not under this name, nor with explicit reference to earlier work. I cite a few recent examples by way of illustration.

Lombardi (1994) observes that a voiced $v s$. voiceless distinction in sonorants is parallelled in many languages by a plain $v s$. aspirated distinction in obstruents. She argues that this patterning supports the view that voicelessness in sonorants should be analysed in terms of the same feature as aspiration in stops. Her reasoning is that if a language uses [aspiration] as a distinctive feature for obstruents, then 'it is natural that it should also use this feature for the voiceless sonorants, and it does not complicate the feature system of the language' (1994: 151). Here is a direct application of feature economy (though not identified as such) to a problem in feature analysis. We shall see more evidence in $\$ 4$ that feature economy provides a powerful tool for feature analysis.

In his discussion of inventories, Boersma (1998: 354) cites feature economy (which he terms the 'maximum use of available features') as guarantor of inventory symmetry. He states that 'most languages seem to have this kind of economically representable grammars', but also notes that articulatory and acoustic constraints counteract this tendency.

McCarthy (1999: 235) identifies feature economy (again not by this name) as one of three major arguments for distinctive features:

Many languages have no sounds from the set $[b d g]$, but if a language has one of them, it is likely to have all of them. These sounds are all $[+$ voice $]$... having the full $[b d g]$ set together in a language maximises the cross-classificatory effect of that distinctive feature.

In a study of what are termed 'segmental modifications' (including secondary articulations, phonation types, nasalisation, and affrication), Hinskens \& van der Weijer (2003 : 1042) defend the following claim:

(5) Hypothesis 1: In segmental inventories types of segmental modification occur on a natural class of segments, rather than randomly or on isolated segments.

This hypothesis is related to feature economy, since if segmental modifications occur on all members of a natural class they are being used with maximal efficiency. Both principles would be supported, for example, by 
a language in which all consonants have labialised counterparts, since in such a language the feature of labialisation occurs on the natural class of consonants (satisfying Hypothesis 1) and is used maximally in consonants (satisfying feature economy). Notice, however, that Hypothesis 1 would also be satisfied by a less economical system in which only a subclass of consonants (such as velar stops) were labialised. Thus Hypothesis 1 presents a weaker claim than feature economy, which requires features to be generalised over all classes of sounds which can theoretically bear them. ${ }^{5}$

Some linguists have proposed to recognise a principle analogous to feature economy operating at the phonetic level. Maddieson (1995) identifies gestural economy as one of the basic principles structuring phoneme inventories. He writes (1995: 574):

There is [a tendency] to be economical in the number and nature of the distinct articulatory gestures used to construct an inventory of contrastive sounds, and it is this (rather than a more abstract featural analysis) that underlies the observed system symmetry.

Maddieson claims, for example, that it is not an abstract feature of labiality but a particular (and perhaps language-specific) labial gesture that is generalised across a given sound system. A similar account is suggested by Bybee, who speaks of a 'strong tendency for speakers to reuse a single set of highly entrenched neuromotor patterns and to substitute members of this set for novel or less common configurations' (2001: 54).

In sum, though feature economy (together with related notions) has not disappeared from the literature, for a principle of such widely acknowledged importance it has received surprisingly little attention in recent work.

\subsection{Diachronic $v s$. synchronic applications of feature economy}

The principle of feature economy was earlier applied mainly to the study of sound change. Martinet observed that isolated phonemes (phonemes which have no counterpart in a given correlative series), such as $/ \mathrm{x} /$ in the system in (6), tend to disappear, to acquire correlative partners (in this case, $/ \mathrm{s} /$ ) or to evolve in such a way as to fill gaps in some other series.

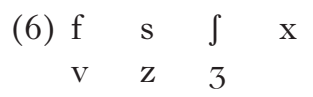

Martinet did not systematically explore the implications of feature economy at the synchronic level. However, it is surely desirable to test feature

${ }^{5}$ Hinskens \& van der Weijer's principle also differs from feature economy in its use of phonetic categories (essentially, the ones used to encode the data in the UPSID phonetic database) instead of phonological features. 
economy in the synchronic domain, where much data is now available and where hypotheses can be more rigorously evaluated without interference from the confounding influence of the various forces that make historical sound change open to conflicting interpretations.

\subsection{Goals of this paper}

The major goal of the present study is to test the predictions of feature economy at the synchronic level, using an objective sampling technique applied to a genetically and areally balanced sample of the world's languages. It will present new evidence that feature economy is one of the basic organising principles of sound systems. A further goal is to show that feature economy is a powerful tool in phonological analysis, enabling linguists to discriminate between competing feature sets and feature analyses.

The remaining discussion is organised as follows. $\S 2$ formulates a central prediction of feature economy, describes the database and presents a method for testing the predictions against the data. $\$ 3$ applies the method to the study of feature-economy effects in various stop and fricative types. $\S 4$ illustrates the use of feature economy as a tool in feature analysis, taking glottal and glottally modified consonants as the object of study; it examines voiced aspirated stops $(\S 4.1)$, voiceless sonorants $(\S 4.2)$, laryngealised and glottalised sounds $(\$ 4.3)$ and implosives $(\$ 4.4)$. $\S 5$ shows that feature economy applies not only to distinctive features, as has been traditionally thought, but to marked values of redundant features as well. \$6 compares feature economy with an alternative principle of gesture economy, and shows that feature economy gives a better account of a broad range of facts. Finally, $\$ 7$ provides a summary and general discussion.

\section{Method}

This section outlines an approach for studying feature-economy effects in sound inventories. $\$ 2.1$ formulates a testable prediction of feature economy, $\$ 2.2$ describes the database and $\$ 2.3$ presents a method for testing feature-economy effects.

\subsection{A prediction of feature economy}

A basic insight underlying feature economy is that speech sounds tend to be composed of features that are used elsewhere in the system. We may test this expectation by formulating it as a prediction that can be tested across a large sample of language. We shall term this MUTUAL aTtRACTION.

(7) Prediction 1

A given speech sound will occur more frequently in systems in which all of its features are distinctively present in other sounds. 
To take an example, many languages have a voiced labial fricative, such as $[\mathrm{v}]$ or $[\beta]$, characterised by the features [labial], [+voiced] and [+continuant]. Let us designate such a sound by upper-case V. By Prediction 1, such a sound should occur more frequently in systems in which [labial], [+voiced] and [+continuant] are distinctively present in other sounds. Thus $\mathrm{V}$ should be commoner in systems having some other labial, some other fricative and some other voiced sound. At least one member of each of these sets must be present in a system for the condition of Prediction 1 to be satisfied.

The economy index $E$ of a system is increased if and only if this condition is satisfied. Addition of $\mathrm{V}$ to any system in which its features [labial], [+voiced] and [+continuant] are already distinctively present will always increase the value of $E$, since the number of features remains constant. But adding $\mathrm{V}$ to a system lacking any one of the three features will introduce both a new unit and a new feature, which always lowers the values of $E .^{6}$

One specific prediction, for example, is that $\mathrm{V}$ should occur more frequently in systems containing both another labial sound and a voiced coronal fricative, which we may designate as $Z$. Since systems containing $\mathrm{V}$ always have other labial sounds, this amounts to saying that $\mathrm{V}$ should be more frequent in systems also containing $Z$. By analogous reasoning, voiced coronal fricatives $Z$ are expected to be more frequent in systems also containing $\mathrm{V}$. It follows that languages having both $\mathrm{V}$ and $\mathrm{Z}$ should be more frequent than would be expected on the basis of the overall cross-linguistic frequencies of $\mathrm{V}$ and $\mathrm{Z}$. One way of testing Prediction 1, then, is to compare the frequencies of $\mathrm{V}$ and $\mathrm{Z}$ across languages. A method for doing this will be described in $\$ 2.3$.

In contrast, feature-economy effects should not be observable between featurally unrelated sounds, such as $\mathrm{F}$ and a liquid L (the very few features shared by $\mathrm{F}$ and $\mathrm{L}$, such as [+consonantal], are likely to be present in a system whether $\mathrm{F}$ and $\mathrm{L}$ are present or not). Comparisons of $\mathrm{F}$ and $\mathrm{L}$ (or similarly unrelated pairs) should reveal no patterns of mutual attraction.

As already noted, Prediction 1 is in conflict with functional constraints which place severe upper limits on how many sounds a system is likely to acquire. If feature economy operated in an untrammelled fashion, a system with $n$ features would have $2^{\mathrm{n}}$ speech sounds. ${ }^{7}$ In fact, no languages come anywhere near this maximum. French, for instance, with its seven consonant features in (3), has only eighteen consonants instead of the $2^{7}=128$ predicted by feature economy in its strongest form. The reason for this shortfall is that most theoretically possible feature combinations are in conflict with requirements of effective speech production and perception. Thus, for example, the fact that audible friction is difficult to produce in

${ }^{6}$ More generally, in any system in which the number of sounds is greater than the number of features, the addition of one new feature supporting just one new sound will always decrease its economy, while the elimination of a single sound and a single feature will always increase its economy.

${ }^{7}$ Or somewhat fewer, if we allow that certain feature combinations are theoretically excluded. 
sounds articulated with nasal airflow explains the fact that most languages avoid nasal fricatives, even when the combination of nasality with frication would increase the economy of the system (Martinet 1952: 25).

For this reason, the majority of exceptions to feature economy are broadly similar across languages: the great majority of languages exclude nasalised fricatives, voiced ejectives, voiceless vowels and so forth. Only in the case of feature combinations that are only marginally dysfunctional (such as voiced stops or nasalised vowels) do we find much cross-linguistic variation.

\subsection{The database}

The database used for this study is UPSID-92, a sample of 451 phoneme systems from the world's languages (Maddieson \& Precoda 1989). This database incorporates most of the earlier inventory of 317 phoneme inventories (UPSID-84) published in Maddieson (1984), which itself draws upon the earlier Stanford Phonology Archive of 196 languages. UPSID92 was selected for several reasons. First, it is the largest database of this type currently available. Given a rough estimate of around 6800 languages currently spoken in the world (Grimes 2000), its 451 languages represent about $6-7 \%$ of the total. Second, UPSID-92 was constructed by selecting just one language from each moderately distant genetic grouping (as measured by the distance between North and West Germanic), a procedure which goes a considerable way toward insuring some degree of genetic balance. Third, the use of a computerised database facilitates rapid searches using query languages such as the one packaged with the database itself. Finally, as UPSID-92 is available to the public from the UCLA Phonetics Laboratory, results obtained from it can be readily checked and compared by researchers using different theoretical approaches.

Nevertheless, as Maddieson (1991a) has pointed out, some caveats are in order. No database is ideal. One problem is that true genetic balance is an unattainable goal, since there is inevitable skewing toward genetic units containing large numbers of languages. Thus, for example, Niger-Congo ${ }^{8}$ is represented in UPSID-92 by 55 languages, Sino-Tibetan by 21 and isolates such as Basque by only one. Though these three units are genetically independent, Niger-Congo is vastly overrepresented with respect to Sino-Tibetan, and both are overrepresented with respect to Basque. The rationale for including 55 Niger-Congo languages must be that these languages have become sufficiently differentiated over time so as to preclude the possibility that existing trends have been inherited from the common ancestor language. However, this is unlikely to be entirely true of relatively stable features, such as place of articulation or voicing in wordinitial position. A related problem is that shared features of geographically

8 This family was formerly known as Niger-Kordofanian, the term used by Maddieson (1984); the older term 'Niger-Congo' has since been reinstated for reasons discussed by Williamson (1989: 19). 
proximate languages are frequently acquired through contact (as in the case of clicks, shared by geographically adjacent Khoisan and Bantu languages; see Janson 1991). For such reasons, many trends in the database are best explained by genetic and areal influences. This means that before concluding that any given trend represents a genuine cross-linguistic generalisation, we must check it for representativity across major genetic units and geographical regions. ${ }^{9}$

A second problem arises from the fact that the inventories included in UPSID have been compiled by many different researchers, who interpret phonetic labels differently and use different theoretical models and criteria in phonemic analysis. No two researchers are likely to agree in all details of any analysis. One major area of disagreement concerns the choice of phonemes. For example, drawing on earlier sources, UPSID lists Ewe as having four nasal stops, even though more recent studies such as Capo (1981) and Bole-Richard (1983) have demonstrated that its nasal consonants are allophones of oral sounds. Another question concerns the choice of the allophone used to code each phoneme; for example, should

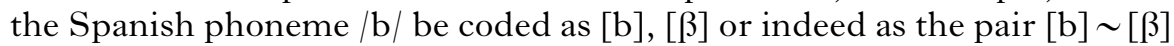
(Simpson 1999)? Other problems include the wide disagreement and inconsistency among researchers in applying terms such as 'dental', 'alveolar', 'palatal', 'implosive', etc., or the sporadic failure to report nondistinctive properties such as apical vs. laminal articulation in anterior coronal sounds (or [ $\pm \mathrm{ATR}]$ in mid vowels), which are distinctive in other languages. For such reasons the full normalisation of phonetic descriptions and analyses in earlier sources is an impossible goal. It is sometimes claimed that such inconsistencies or errors will cancel themselves out over the long run, but this is unlikely to be so in all cases.

A third problem concerns clerical errors involving miscopying, etc.; see Basbøll (1985) for a sample of coding errors in the original version of UPSID. In my work with UPSID-92 I have discovered a fair number of further discrepancies between the data and the original sources. Such errors may not be significant in the case of broadly based trends, but can become important when generalisations (or exceptions to generalisations) are based on just a few languages. In such cases, the crucial data should be checked against the original sources (see $\$ 4.4$ for an example).

In sum, while UPSID-92 is a valuable tool for research on sound systems, it must be interpreted with care.

\subsection{Controlling for genetic or areal skewing}

To control for genetic or areal skewing, observed trends must be tested across all genetic and areal groups for which sufficient data are available. To achieve this, separate tests are currently being run on the eleven units

9 As Maddieson also points out (1991b), the possibility of remote genetic relationships among presently recognised genetic units adds to the problems discussed here. 
shown in Table II, all of which contain 20 or more members in the UPSID-92 database.

Eurasia Indo-European (23), Ural-Altaic (28), Austro-Tai (39), Sino-Tibetan (21)

Africa Niger-Congo (55), Nilo-Saharan (23), Afro-Asiatic (26)

Americas North American (58), South American (66)

Australasia Australian (25), Papuan (39)

\section{Table II}

Language units selected to test for possible genetic skewing. The number of languages in each unit represented in UPSID-92 is shown in parentheses.

Genetic or areal skewing will show up as the restriction of a trend to certain genetic units or contiguous regions.

\subsection{Feature coding}

To test Prediction 1, the phoneme systems of UPSID-92 were coded in terms of a standard model of distinctive features. For this purpose a selection of features has been drawn from the feature sets of Sagey (1990), Halle (1992) and Clements \& Hume (1995), which are essentially equivalent as far as the sounds discussed here are concerned. For consonants, these include those shown in (8):

(8) a. one-valued

[labial], [coronal], [dorsal], [radical], [spread glottis], [constricted glottis]

b. two-valued

[sonorant], [consonantal], [distributed], [anterior], [strident], [lateral], [voice], [nasal], [continuant]

As this list shows, features are classified as one-valued or two-valued, depending on their phonological behaviour (Sagey 1990).

Feature-economy effects are not tied to the specifics of the system in (8). This system does not differ radically from the Prague School feature system within which feature-economy effects were first detected. The two feature sets share the following characteristics: ${ }^{10}$ (i) most features are defined in articulatory terms; (ii) most manner features are two-valued; (iii) most place features are one-valued. Many features are common to both systems. Natural classes defined by the two systems are also very similar. The system in (8) differs from the Prague system mainly in its inclusion of the articulator-based features [labial], [coronal] and [dorsal] instead of more specific place of articulation features such as labiodental, apicodental and velar. Even with this difference, however, the systems are easily comparable.

${ }^{10}$ Here we distinguish 'place' and 'manner' features, both distinguished from 'major class' features, for purely expository purposes. 


\subsection{Statistical analysis}

The basic method used for the evaluation of implicational universals is the comparison of observed vs. expected distributions of selected sounds (Maddieson 1991b). This method is applicable to the study of featureeconomy effects as well. Frequencies of selected sets of sounds are compared in order to determine the number of languages having: (i) each member of the set; (ii) all members of the set; (iii) no members of the set. For example, if two sound types, A, B, are under comparison, the number of languages having $\mathrm{A}$ alone, $\mathrm{B}$ alone, both $\mathrm{A}$ and $\mathrm{B}$ and neither $\mathrm{A}$ nor $\mathrm{B}$ is determined. Numbers are arrayed in contingency tables, and observed values are compared with expected values to test the null hypothesis that the distributions of $\mathrm{A}$ and $\mathrm{B}$ across the sample are independent of each other. The differences between observed and expected frequencies are tested for significance by the chi square $\left(\chi^{2}\right)$ test. This test is commonly used to determine whether two characteristics are independent or associated in such a way that high frequencies of one tend to be coupled with high frequencies of the other. It is therefore appropriate here. However, several precautions must be taken in interpreting $\chi^{2}$ test results.

2.5.1 Cells with very small values. First, tables containing cells whose expected values are five or under must be avoided as far as possible, since in such comparisons one of the assumptions underlying the $\chi^{2}$ test, that the values correspond to a continuous rather than a discrete frequency distribution, is not valid. In cases where such tables must be used, $\chi^{2}$ values should be calculated using Yates's continuity correction, which yields smaller values and makes a more conservative projection of significance levels. Yates's correction is used in this study on all tables containing cells with values of seven or less.

This limitation on the use of the $\chi^{2}$ test raises a problem not only for comparisons involving sounds found in very few languages, but also (perhaps less obviously) for sounds found in nearly all languages, such as voiceless stops, since in such comparisons cells showing the number of languages expected to lack these sounds will usually contain a total of five or less. However, this problem is only apparent, as it makes little sense to seek feature-economy effects involving these common sound types in the first place. Since nearly all languages have them, their cross-linguistic frequency cannot be significantly increased by the presence of other sounds; these segment types are universally favoured, and come for free, as it were. In contrast, less favoured sound types involve a cost, but feature economy predicts they will cost less if the system already has other sounds bearing their features. It is the relations among such sounds that will concern us here.

2.5.2 Covert attractors and subset effects. A more serious problem is that a statistically significant association between A and B does not necessarily demonstrate a direct relation between $\mathrm{A}$ and $\mathrm{B}$. The association may instead be due to the covert influence of a third term, $\mathrm{C}$, which is associated with both $\mathrm{A}$ and $\mathrm{B}$. 
a. covert attractor

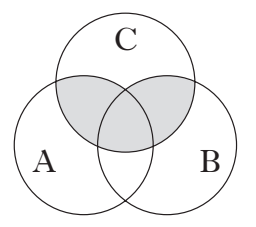

b. subset effect

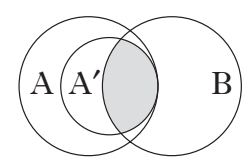

Figure 1

In (a), an apparent association between A and B (innermost shaded area) is due to the presence of a 'covert attractor' $\mathrm{C}$, which is associated with both $\mathrm{A}$ and $\mathrm{B}$. In (b), an apparent association between $\mathrm{A}$ and $\mathrm{B}$ is entirely due to subset $\mathrm{A}^{\prime}$.

Such 'covert attractors' can usually be detected by performing a new comparison within the subset of the database from which languages having the suspected attractor have been removed. For example, the UPSID data reveal a weak positive association between voiced stops and voiced fricatives $\left(\chi^{2}=4 \cdot 772, \mathrm{p}<0 \cdot 05\right)$. However, further study reveals a strong positive association between voiced stops and voiceless fricatives $\left(\chi^{2}=15 \cdot 312, \mathrm{p}<0 \cdot 0001\right)$ and between voiceless fricatives and voiced fricatives $\left(\chi^{2}=22 \cdot 377, \mathrm{p}<0.0001\right)$. When we restrict our search to the 45 languages lacking voiceless fricatives, the observed number of languages having both voiced stops and voiced fricatives is strictly identical to the expected number (three in both cases). Voiceless fricatives are thus 'covert attractors' between voiced stops and voiced fricatives. ${ }^{11}$

A related problem is that a positive association between $\mathrm{A}$ and $\mathrm{B}$ may be due to a subset of $\mathrm{A}$ rather than to $\mathrm{A}$ as a whole. For example, the positive association between glottals and voiceless coronal fricatives proves to be due just to voiceless H-sounds, a subset of glottals. Such 'subset effects' can be detected by running a new comparison between the suspected subset $\mathrm{A}^{\prime}$ (in this case, voiceless $\mathrm{H}$-sounds) and $\mathrm{B}$, and another between the complement of $\mathrm{A}^{\prime}$ (voiced H-sounds and glottal stops) and B. If a subset effect is present, the $\chi^{2}$ value and significance level of the comparison involving $\mathrm{A}^{\prime}$ will be higher than in the comparison involving $\mathrm{A}$ as a whole, and the comparison involving the complement of $\mathrm{A}^{\prime}$ will prove non-significant or negative. These two situations are illustrated schematically in Fig. 1.

\subsection{A comparison of $\mathrm{V}$ and $\mathrm{Z}$}

To illustrate this method we may compare the frequencies of voiced labial fricatives $\mathrm{V}$ and voiced coronal fricatives $\mathrm{Z}$ across the UPSID inventories.

11 One might ask whether it is instead the association between voiceless fricatives and voiced stops that is spurious, since they have no manner feature in common. Could this association be explained by the covert influence of voiced fricatives, which share a feature with each? Separate tests show that this is not the case: the association between voiceless fricatives and voiced stops holds even in the subset of the data from which voiced fricatives have been removed $\left(\chi^{2}=7 \cdot 807, \mathrm{p}<0 \cdot 01\right)$. 
In this study upper-case letters are used to designate general sound types as defined by phonological features, and lower-case letters are reserved for specific phonetic categories. Thus $\mathrm{V}$ represents the broad class of voiced labial fricatives, and thus includes bilabial and labiodental fricatives, while [v] represents the voiced labiodental - but not bilabial - fricative.

Adding either $\mathrm{V}$ or $\mathrm{Z}$ to a system already containing the other will almost invariably increase its economy index $E$. This is because the overwhelming majority of languages have consonants at both labial and coronal places of articulation; adding a second voiced fricative $\mathrm{Z}$ or $\mathrm{V}$ to such a system will necessarily increase its economy. This is shown in (9) for typical systems containing the voiceless stops $\mathrm{P}, \mathrm{T}$ and the voiceless fricatives $\mathrm{F}, \mathrm{S}$.

(9) subsystem $A$

\begin{tabular}{llll}
\multicolumn{2}{l}{ subsystem $B$} & \multicolumn{3}{c}{ subsystem } \\
$\mathrm{P}$ & $\mathrm{T}$ & $\mathrm{P}$ & $\mathrm{T}$ \\
$\mathrm{F}$ & $\mathrm{S}$ & $\mathrm{F}$ & $\mathrm{S}$ \\
& $\mathrm{Z}$ & $\mathrm{V}$ & $\mathrm{Z}$
\end{tabular}

All these systems require the three marked features [labial], [+voiced], [+continuant $]$ :

$\begin{array}{ll}\text { [labial }] & \mathrm{P} \text { vs. } \mathrm{T} \\ \text { [+voiced }] & \mathrm{F} \text { vs. } \mathrm{V} \text { and/or } \mathrm{S} \text { vs. } \mathrm{Z} \\ \text { [+continuant }] & \mathrm{P} \text { vs. } \mathrm{F}\end{array}$

In the first two systems these features yield an economy index of 1.67 $(S=5, F=3, S / F=1 \cdot 67)$. System $C$, which adds the missing voiced fricative, thereby 'filling the gap', achieves an economy index of $2 \cdot 00$. Subsystem $C$ is thus the most economical of the three.

The expectation under Prediction 1 (Mutual Attraction), then, is that the voiced fricatives $\mathrm{V}$ and $\mathrm{Z}$ should be positively associated with each other in frequency due to their shared features [+continuant] and [+voiced]. In other words, more languages should have both $\mathrm{V}$ and $\mathrm{Z}$ in their consonant inventories than would be expected on the basis of their independent frequencies in the sample as a whole.

To test this prediction, a $2 \times 2$ contingency table is constructed as shown in Table III :

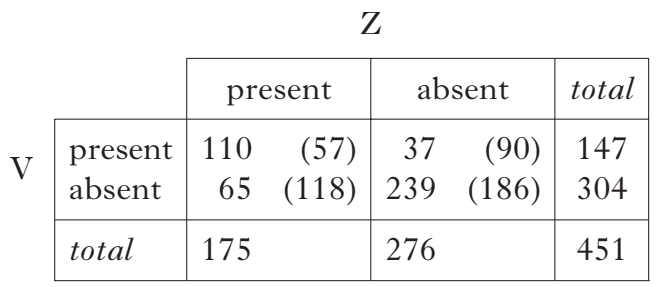

Table III

Contingency table showing observed frequencies of $\mathrm{V}$ (voiced labial fricatives) and $Z$ (voiced coronal fricatives) across languages in UPSID-92. Expected frequencies are shown in parentheses. 
This table partitions the UPSID languages into four subsets, corresponding to the four cells. It shows that of the total of 451 languages in the sample, 110 have both $V$ and $Z, 37$ have $V$ but not $Z, 65$ have $Z$ but not $V$, and 239 have neither $\mathrm{V}$ nor $\mathrm{Z}$. These are the observed frequencies of each subset.

The expected frequency of each cell is calculated on the assumption that the frequency of $\mathrm{V}$ or $\mathrm{Z}$ in each subset is proportional to its frequency in the sample as a whole (as would be the case if Prediction 1 is false). This frequency, shown in parentheses, is given by $\left(\mathrm{T}_{\mathrm{R}} * \mathrm{~T}_{\mathrm{C}}\right) / \mathrm{T}$, where $\mathrm{T}_{\mathrm{R}}$ and $\mathrm{T}_{\mathrm{C}}$ are the row and column totals corresponding to the cell in question and $\mathrm{T}$ is the total sample size. Of particular interest is the expected frequency of languages having both $\mathrm{V}$ and $\mathrm{Z}$, as shown in the upper lefthand cell. The expected frequency in this cell is $(147 * 175) / 451$, which (after rounding) gives 57. Since the observed frequency in this cell (110) is higher than this, the association between $\mathrm{V}$ and $\mathrm{Z}$ is positive. This means that languages having one of these sounds tend to have the other.

We next ask whether this association is significant. The probability that a given cell value is due to chance (the null hypothesis) is calculated on the basis of the differences between observed and expected values in all cells (Butler 1985). In Table III the discrepancies are very large and prove to be highly significant $\left(\chi^{2}=119 \cdot 203, p<0 \cdot 0001\right)$. We may conclude that the association between $\mathrm{V}$ and $\mathrm{Z}$ across the sample is not only positive, but significantly so.

This result confirms Prediction 1 for this pair of sounds. We must still ask, however, whether it could be due to genetic or areal skewing. An examination of the $\mathrm{V} / \mathrm{Z}$ distribution in each of the eleven units in Table II reveals a positive association between $\mathrm{V}$ and $\mathrm{Z}$ in nine of them. The other units (Australian, Nilo-Saharan) show neither a positive nor a negative association (only three of the 25 Australian languages have fricatives at all). We conclude that the association between $\mathrm{V}$ and $\mathrm{Z}$ is not due to the undue influence of any one group in the sample. Prediction 1 is therefore confirmed at the cross-linguistic level.

\section{Results}

This section applies the method just outlined to several test cases. It first shows that manner features tend to generalise across places of articulation, in accordance with Prediction 1 ( $\$ 3.1)$. It then examines, and confirms, a second prediction of feature economy, according to which isolated sounds (i.e. sounds containing features not found in other sounds) tend to be disfavoured (\$3.2). It finally examines cases in which feature-economy effects generalise across manner categories $(\S 3.3)$.

\subsection{Feature-economy effects involving manner features}

Comparisons were made among several pairs of stops sharing all manner features but differing in place, as shown in Table IV. Stops are defined to 
include plosives and affricates. Given that the vast majority of languages have consonants at each major place of articulation (labial, coronal, dorsal), all associations are expected to be positive.

a. \begin{tabular}{|c|c|c|}
\hline $\mathrm{P}^{-}$vs. $\mathrm{T}^{-}$ & $\mathrm{P}^{\mathrm{h}} v s . \mathrm{T}^{\mathrm{h}}$ & $\mathrm{P}^{\prime} v s . \mathrm{T}^{\prime}$ \\
$\mathrm{P}^{-}$vs. $\mathrm{K}^{-}$ & $\mathrm{P}^{\mathrm{h}} v s . \mathrm{K}^{\mathrm{h}}$ & $\mathrm{P}^{\prime} v s . \mathrm{K}^{\prime}$ \\
$\mathrm{T}^{-}$vs. $\mathrm{K}^{-}$ & $\mathrm{T}^{\mathrm{h}} v s . \mathrm{K}^{\mathrm{h}}$ & $\mathrm{T}^{\prime} v s . \mathrm{K}^{\prime}$ \\
\hline $\mathrm{B} v s . \mathrm{D}$ & $\mathrm{B}^{\mathrm{h}} v s . \mathrm{D}^{\mathrm{h}}$ & $\mathrm{B}^{<} v s . \mathrm{D}^{<}$ \\
$\mathrm{B}$ vs. $\mathrm{G}$ & $\mathrm{B}^{\mathrm{h}}$ vs. $\mathrm{G}^{\mathrm{h}}$ & $\mathrm{B}^{<}$vs. $\mathrm{G}^{<}$ \\
$\mathrm{D}$ vs. $\mathrm{G}$ & $\mathrm{D}^{\mathrm{h}}$ vs. $\mathrm{G}^{\mathrm{h}}$ & $\mathrm{D}^{<}$vs. $\mathrm{G}^{<}$ \\
\hline
\end{tabular}

Table IV

Comparisons among pairs of stops sharing all manner features, but differing in place. ( $\mathrm{P} \mathrm{B}=$ labial stops; $\mathrm{T} \mathrm{D}=$ coronal stops; $\mathrm{KG}=$ dorsal stops.) (a) plain voiceless stops, voiceless aspirated stops, ejective stops; (b) voiced unaspirated stops, voiced aspirated stops, implosives.

As before, upper-case letters represent general categories, as explained in the legend. All these comparisons tested positive at a very high level of significance $(p<0 \cdot 0001)$. That is, languages having one member of each pair tend overwhelmingly to have the other. ${ }^{12}$

Similar comparisons can be made for pairs of voiceless and voiced fricatives, as shown in Table $\mathrm{V}$ ( $\Gamma$ represents any voiced dorsal fricative, whether velar or uvular).

\begin{tabular}{|c|c|c|}
\hline F vs. $\mathrm{S}$ & Fvs. $\mathrm{X}$ & $\mathrm{S} v s . \mathrm{X}$ \\
\hline V vs. $\mathrm{Z}$ & V vs. $\Gamma$ & $\mathrm{Z} v s . \Gamma$ \\
\hline
\end{tabular}

Table $V$

Comparisons between voiceless and voiced fricatives at different places of articulation ( $\mathrm{F}$ V = labial fricatives; $\mathrm{S} \mathrm{Z}=$ coronal fricatives;

$$
\mathrm{X} \Gamma=\text { dorsal fricatives). }
$$

Again, all results were positive and significant at the $0 \cdot 0001$ level, except for the $\mathrm{F}$ vs. $\mathrm{X}$ comparison, which only reached the $0 \cdot 05$ level.

These results strongly confirm Prediction 1 for these comparisons. They show that manner features tend to generalise across the major places of articulation.

\subsection{Avoidance of isolated sounds}

This section shows that the preference for sounds whose features are found in other sounds ('integrated sounds') is complemented by a dispreference

12 Note, however, that the results for voiced aspirates and implosives do not necessarily reflect broadly based typological characteristics, since these sounds are not widely distributed among the sample languages. 
for sounds whose features are not shared by other sounds ('isolated sounds').

The dispreference for isolated sounds, as already noted in $\$ 2.1$, follows from feature economy. This point can be illustrated by the subsystems in (11):

$\begin{array}{llll} & \text { subsystem } A & \text { subsystem } B & \text { subsystem } C \\ & \mathrm{P} \mathrm{T} & \mathrm{P} \mathrm{T} & \mathrm{P} \mathrm{T} \\ & & \mathrm{B} & \mathrm{B} \quad \mathrm{D} \\ \text { features } & {[\text { labial] }} & {[\text { labial], [voiced] }} & {[\text { labial], [voiced] }} \\ E(S / F) & 2.00 & 1.50 & 2 \cdot 00\end{array}$

Subsystem $A$, containing only voiceless stops $\mathrm{P} \mathrm{T}$, uses one feature ([labial] $v s$. its absence) to characterise two stops; its economy index is $2 / 1$, or 2.00. Subsystem $B$, adding just the voiced stop $B$, uses two features ([labial], [voiced]) to characterise three stops; its economy index is $1 \cdot 50$. In this system, B is an 'isolated' sound, as it has no counterpart at the coronal place of articulation; adding $\mathrm{B}$ to a system with $\mathrm{P}$ and $\mathrm{T}$ but no $\mathrm{D}$ lowers its economy index. Only if the inventory already contains another voiced stop, as does subsystem $C$, does the addition of $\mathrm{B}$ raise its index.

On the basis of this reasoning we may formulate a second prediction, which we call AvoIdAnce of IsOLATEd Sounds:

\section{(12) Prediction 2}

A given speech sound will have a lower than expected frequency in systems in which one or more of its features are not distinctively present in other sounds.

For example, this principle disfavours the isolated sound B in subsystem $B$ of (11), as one of its features, [+voiced], is not distinctively present in other sounds.

With this background, let us compare the frequencies of stops and fricatives in systems in which they are integrated with the frequencies of the same sounds in systems in which they are isolated. We first examine the frequencies of the labial consonants $\mathrm{P}, \mathrm{B}, \mathrm{F}$ and $\mathrm{V}$ in systems in which they are supported by other sounds bearing the same manner features. The expectation under Prediction 1 (Mutual Attraction) is that all comparisons should be positive. Results are summarised in Table VI. Expected and observed frequencies are shown for each comparison.

As predicted, all comparisons are positive $(\mathrm{p}<0.0001$ in all cases). The first row shows, for example, that $\mathrm{P}$ occurs in 407 systems containing $\mathrm{T}$ and/or K, instead of the 402 systems that would have been expected in the absence of feature-economy effects. Thus the presence of $\mathrm{T}$ and/or $\mathrm{K}$ favours the presence of $\mathrm{P}$. The other consonants follow the same pattern. Prediction 1 is therefore confirmed: all consonants occur with a higher than expected frequency in systems in which they are supported by other consonants bearing the same features. 
Feature economy in sound systems

\begin{tabular}{|c|c|c|c|}
\cline { 2 - 4 } \multicolumn{1}{c|}{} & in systems with & expected & observed \\
\hline P & either T or K & 402 & 407 \\
B & either D or G & 233 & 310 \\
F & either S or X & 194 & 214 \\
V & either Z or $\Gamma$ & 60 & 112 \\
\hline
\end{tabular}

Table VI

Frequency of occurrence of P B F V in systems containing other consonants with the same manner features.

Now let us consider, in contrast, the frequencies of $\mathrm{P}, \mathrm{B}, \mathrm{F}$ and $\mathrm{V}$ in systems that do not contain other consonants with the same manner features. These are shown in Table VII.

\begin{tabular}{|c|c|c|c|}
\cline { 2 - 4 } \multicolumn{1}{c|}{} & in systems without & expected & observed \\
\hline P & both T and K & 5 & 0 \\
B & both D and G & 89 & 12 \\
F & both S and X & 24 & 4 \\
V & both Z and $\Gamma$ & 87 & 35 \\
\hline
\end{tabular}

Table VII

Frequency of occurrence of P B F V in systems not containing other consonants with the same manner features.

This time all comparisons are strongly negative: the absence of both $\mathrm{T}$ and $\mathrm{K}$ disfavours $\mathrm{P}$, and so forth $(\mathrm{p}<0.0001$ in all cases). This confirms that 'isolated' sounds - those bearing features not found elsewhere in the system - tend to be avoided.

Similar tests were run for the coronals T, D, S and $\mathrm{Z}$ and the dorsals $\mathrm{K}$, $\mathrm{G}, \mathrm{X}$ and $\Gamma$. The results were analogous in all cases, and at the same high level of significance $(p<0 \cdot 0001)$. Thus Predictions 1 and 2 are strongly confirmed: for the comparisons examined here, integrated sounds are favoured and isolated sounds are disfavoured.

\subsection{Cross-category feature economy}

A further case in which feature-economy effects are predicted involves what can be termed CROSS-CATEGORY ECONOMY. This involves the generalisation of an existing feature to a new manner of articulation type, defined in terms of independently occurring features. For example, given a system containing $\mathrm{P}, \mathrm{B}$ and $\mathrm{F}$, we expect the distinctive features of voicing and continuance to combine to create a voiced fricative $\mathrm{V}$, since the presence of this sound will increase the economy of the system. 
As an illustration, let us consider the subsystems shown in (13):

$\begin{array}{lll} & \text { subsystem } A & \text { subsystem } B \\ & \mathrm{P} \mathrm{F} & \mathrm{P} \mathrm{F} \\ \mathrm{B} & \mathrm{B} \mathrm{V} \\ \text { features } & \text { [voiced], [continuant] } & \text { [voiced], [continuant] } \\ E(S / F) & 1.50 & 2 \cdot 00\end{array}$

Subsystem $A$, which uses the features [+voiced] and [+continuant] to distinguish three consonants, has an economy index of $1 \cdot 50$. Subsystem $B$, using the same features to characterise four consonants, has an economy index of $2 \cdot 00$. Note that by adding $\mathrm{V}$, this system integrates the previously isolated consonants $\mathrm{F}$ and $\mathrm{B}$.

The database was examined to see whether $\mathrm{V}$ is indeed more frequent than expected in systems containing $\mathrm{P}, \mathrm{F}$ and $\mathrm{B}$. Results are shown in Table VIII.

P B F

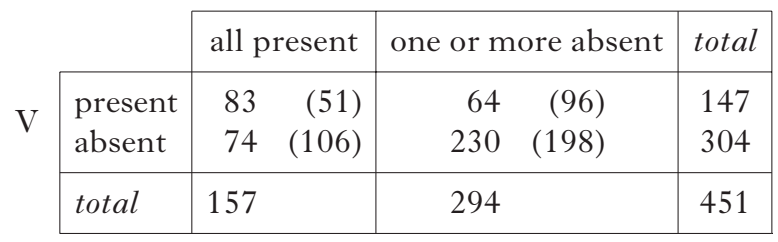

Table VIII

Observed and expected frequencies of $\mathrm{V}$ in languages that do (left column) vs. do not (right column) contain all the sounds P B F.

Expected frequencies are shown in parentheses.

We see that $\mathrm{V}$ is considerably more frequent than expected in languages having all three of the sounds $\mathrm{P}, \mathrm{B}$ and $\mathrm{F}$, and considerably less frequent in languages lacking any of them $\left(\chi^{2}=45 \cdot 049, \mathrm{p}<0 \cdot 0001\right)$. The prediction is again confirmed. This is an instance, then, of 'cross-category' feature economy, applying to favour a new manner of articulation type, in this case voiced fricatives.

To confirm these results at other places of articulation, similar tests were run for the occurrence of: (i) $Z$ (any voiced coronal fricative) in systems containing T, D and S; (ii) $\Gamma$ (any voiced dorsal fricative) in systems containing $\mathrm{K}, \mathrm{G}$ and $\mathrm{X}$. All tested positive at the same high level of significance $(\mathrm{p}<0.0001)$. We conclude that cross-category feature economy is strongly confirmed: systems containing distinctive voiced stops and voiceless fricatives tend strongly to have distinctive voiced fricatives as well. Further cross-category effects, involving other features, will be discussed in $\S 4$. 


\subsection{Summary}

This section has tested feature-economy effects in synchronic data with a variety of consonant comparisons. In accordance with Prediction 1 (Mutual Attraction), manner features were found to generalise across independently occurring places of articulation. A new prediction (Avoidance of Isolated Sounds) was formulated and confirmed in further comparisons. Finally, features were shown to generalise to new manner of articulation types whose other features are already present elsewhere in the system (cross-category feature economy).

\section{Feature economy as a tool in phonological analysis}

The discussion up to now has provided strong cross-linguistic evidence for the principle of feature economy. In some cases, such as most of those discussed up to now, it is fairly clear which features are shared by selected pairs of sounds. There is little serious doubt, for instance, that [v] bears the features [labial] and [+voiced]. In other cases, though, feature analysis is less evident, or frankly problematical. In the past, feature analyses have been based largely upon studies of the way sounds pattern in phonotactic constraints and morpheme alternations. However, such evidence is not always abundant or easily extracted from source materials, and tends to be cited in an anecdotal fashion, with sometimes contradictory results.

This section explores the use of feature economy as a new tool for testing theories of feature structure. We consider in turn the feature analysis of voiced aspirated stops $(\S 4.1)$, voiceless sonorants $(\$ 4.2)$, glottalised sounds $(\$ 4.3)$ and implosives $(\$ 4.4)$.

\subsection{Voiced aspirated stops}

We first compare two possible analyses of voiced aspirated stops, a class of sounds including what are often called 'breathy voiced' and 'murmured' stops. In traditional phonetic classifications, these sounds have been characterised by special features of breathiness or murmur, alone or in conjunction with voicing. For example, UPSID classifies these sounds as 'breathy' and 'voiced' and recognises no class of 'aspirated' voiced sounds other than voiced $h$. In more recent phonological theory, in contrast, voiced aspirated stops have been characterised by features such as [spread glottis] and [+voiced] (e.g. Halle \& Stevens 1971, Lombardi 1994). Each of these features is used to characterise other sounds as well; in particular, [spread glottis] characterises voiceless aspirated stops and [+voiced] ordinary voiced stops.

Both accounts are consistent with the phonetic realisation of these sounds, which are typically produced with the vocal folds held loosely open along part of their length (Kagaya \& Hirose 1975, Benguerel \& Bhatia 1980, Dixit 1989, Davis 1994). The theoretical question, then, is 
whether we need a feature [breathy] in addition to [+voiced] and [spread glottis]. Feature economy provides a new criterion for evaluating this question. If voiced aspirated stops are characterised by the features [+voiced] and [spread glottis], they should be more frequent in languages that have other sounds bearing these features. Let us see whether this is true.

Ten languages in the UPSID-92 survey have voiced aspirated stops, occurring in six language families and two geographic zones:

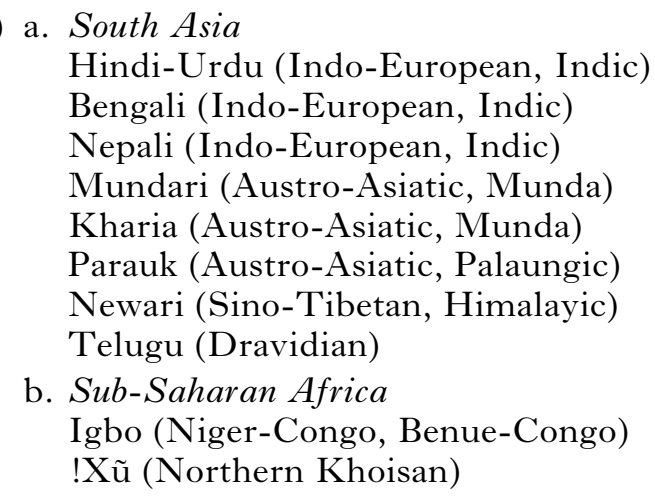

Of these languages, all have both plain voiced stops and voiceless aspirated stops, usually at corresponding places of articulation. That is, there is a strict implication from the presence of voiced aspirated stops in an inventory to each of the two other categories. ${ }^{13}$

This generalisation is further supported by the sound inventories of 69 languages of India compiled by Pandey (2003). 26 of these have voiced aspirated stops. Of these, all have plain voiced stops and voiceless aspirates as well, though the latter are listed as marginal in one language (DidayiGtaP).

Another prediction of a theory treating voiced aspirated sounds with the features [spread glottis] and [+voiced] is that they should tend to associate with voiced $h$ (IPA [6]) through a further effect of cross-category feature economy. This too is confirmed in the UPSID database. Voiced $h$ is infrequent in the sample as a whole (only ten out of 451 languages are reported to have it), but it occurs in five of the sixteen languages which have voiced aspirated stops. This distribution is highly significant $\left(\chi^{2}=51 \cdot 382, \mathrm{p}<0 \cdot 0001\right)$.

Another prediction is that voiced aspirated stops should tend to associate with breathy voiced sonorants. Breathy voiced sonorants occur in four languages in the survey, Hindi-Urdu, Parauk, Newari and !Xũ, where they contrast with modally voiced sonorants. All these languages have breathy voiced obstruents as well.

13 Due to the small numbers involved, only the relation between voiced aspirated stops and voiceless aspirates reaches significance $\left(\chi^{2}=25 \cdot 092, \mathrm{p}<0 \cdot 0001\right)$. 
These various observations converge on the view that voiced aspirated sounds are just what their name implies: sounds characterised by the features [+voiced] and [spread glottis]. They go unaccounted for in a theory in which breathy voice is treated in terms of a special feature of its own. ${ }^{14}$

Another conclusion can be drawn from these results. Since feature economy applies across different phonetic categories (voiceless aspirated stops, modally voiced stops, voiced aspirated stops, voiced $h$, breathy voiced sonorants), most of which involve different glottal configurations, it provides evidence that feature economy applies to phonological features (as was originally supposed) rather than to specific articulatory gestures. We shall see more evidence for this view below.

\subsection{Voiceless sonorants}

So-called voiceless sonorants (nasals and approximants) present a different problem for feature analysis: their voicelessness can potentially be accounted for by either of two independently motivated features, [-voiced] or [spread glottis]. Traditionally, voiceless sonorants have been viewed simply as [-voiced], as their name implies. Following this tradition, UPSID contains entries for voiceless sonorants, but none for aspirated sonorants. However, other accounts have suggested that they may be more accurately characterised by the feature [spread glottis] (Halle \& Stevens 1971, Clements 1985, Mester \& Itô 1989, Lombardi 1994). As both of these features are provided by the theory, each is theoretically combinable with sonorants.

Let us see, then, whether we can find relevant feature-economy effects. If voiceless sonorants are characterised by [spread glottis], they should tend to occur with higher than expected frequency in systems containing aspirated obstruents and/or H-sounds.

31 languages in the survey have voiceless sonorants. Their frequency is compared with that of aspirated sounds in Table IX. The category of aspirated sounds (ASP) includes H-sounds on the one hand and aspirated obstruents (i.e. voiceless aspirated, breathy voiced, breathy voiceless) on the other.

14 Somewhat more puzzling is the status of breathy voiceless stops, which are voiceless during their occlusion and breathy voiced at their release. Two languages in the UPSID database, Javanese and Wu (Changzhou dialect), to which we can add Shanghai (another $\mathrm{Wu}$ dialect), have been described in these terms. In their discussion of these cases, Ladefoged \& Maddieson (1996) interpret these stops as bearing a phonetic feature of slack voice, having characteristics intermediate between modal and breathy voice. However, none of these languages has a contrasting voiced stop series (whether modal or breathy), opening the possibility that these stops, too, might be treated as voiced aspirated at the phonological level, with the laryngeal features [spread glottis] and [+voiced] timed to coincide with the release in their articulatory realisation. If this analysis is correct, these languages would have breathy voiced stops but no plain voiced stops, contrary to the majority trend. (Thanks to Moira Yip for calling Shanghai to my attention.) 


\begin{tabular}{|l|c|c|c|r|r|}
\hline comparison & $\exp$ & obs & association & \multicolumn{1}{|c|}{$\chi^{2}$} & \multicolumn{1}{|c}{} \\
\hline VL SON vs. ASP (H, OBS) & 21 & 28 & positive & $7 \cdot 707$ & $\mathrm{p}<0 \cdot 01$ \\
VL SON $v s$. H & 21 & 27 & positive & $7 \cdot 286$ & $\mathrm{p}<0 \cdot 01$ \\
VL SON vs. ASP OBS & 8 & 18 & positive & $17 \cdot 535$ & $\mathrm{p}<0.0001$ \\
\hline
\end{tabular}

Table IX

Comparison of voiceless sonorants with aspirated sounds (H-sounds, aspirated obstruents) (exp = expected; obs = observed).

This table presents comparisons in summary form, showing only information from contingency tables of the type shown in Table III that bears crucially on feature-economy effects. The first column ('comparison') identifies the sounds being compared; the second ('exp') shows the number of languages expected to have both sounds (assuming their frequencies to be independent of each other); the third ('obs') shows the number of languages actually observed to have both sounds; the fourth ('association') states whether the association is positive (obs $>\exp$ ) or negative (exp $>$ obs); and the last two show $\chi^{2}$ values and significance levels.

All rows show strong positive associations between voiceless sonorants and aspirates. The first row compares voiceless sonorants with the full class of aspirates. The next two look for potential subset effects by examining $\mathrm{H}$-sounds and aspirated obstruents separately. Both comparisons remain positive at the same level of significance or higher. The association between voiceless sonorants and aspirated obstruents, shown in the last row, is especially strong; while aspirated obstruents occur in only $27 \%$ of the sample languages as a whole, they occur in $58 \%$ of the languages having voiceless sonorants. These results provide strong support for the view that voiceless sonorants are characterised by the feature [spread glottis].

\subsection{Laryngealised sounds, ejectives and glottal stops}

Let us next consider whether laryngealised sounds have a feature in common with ejectives and glottal stops. Laryngealised sounds involve some type of laryngeal constriction (such as 'creaky voice', 'laryngeal tension' or pre- or post-glottalisation) superimposed on a pulmonic egressive airstream (Ladefoged \& Maddieson 1996), and also include laryngealised or glottalised implosives (for these see Pinkerton 1986, Demolin 1995). In contrast, ejective sounds are produced with a glottalic egressive airstream mechanism. The various types of laryngealised sounds differ considerably among themselves in details of their realisation, and they are different in still other respects from ejectives and glottal stops (see e.g. Gordon 2001, Howe \& Pulleyblank 2001, Um 2001, Wright et al. 2002). For this reason, all these sounds have been traditionally assigned to different phonetic categories. (UPSID groups preglottalised and laryngealised sounds into a single category 'laryngealised', but divides ejectives into two separate categories, ejective plosives and ejective affricates.) If feature economy 
operated at the level of such diverse categories, we would expect to find no feature-economy effects among them.

Phonological analysis, in contrast, has tended to group all these sounds into a single class of glottalised sounds. In the feature system of Chomsky $\&$ Halle (1968), for example, all these sounds, as well as glottal stops, share the feature [glottal constriction]. This analysis was continued by Halle \& Stevens (1971), who renamed the feature [constricted glottis], and by Lombardi (1994), who renamed it [glottalisation]. As this feature is often distinctive in consonants, it should be able to create 'cross-category' feature-economy effects among all these various types of sounds.

We will compare the three relevant categories included in UPSID: laryngealised sounds (including all varieties described above), ejectives (plosives and affricates) and glottal stops. Results of the comparisons are given in Table X, following the model of Table IX.

\begin{tabular}{|l|r|c|c|c|c|}
\hline comparison & exp & obs & association & $\chi^{2}$ & \multicolumn{1}{|c}{} \\
\hline LAR vs. EJECT & 7 & 19 & positive & $25 \cdot 705$ & $\mathrm{p}<0 \cdot 0001$ \\
LAR vs. $P$ & 22 & 40 & positive & $33 \cdot 664$ & $\mathrm{p}<0 \cdot 0001$ \\
EJECT vs. ? & 33 & 55 & positive & $33 \cdot 045$ & $\mathrm{p}<0 \cdot 0001$ \\
\hline
\end{tabular}

Table $X$

Comparison of laryngealised sounds, ejectives and glottal stops.

All comparisons are strongly positive. The first shows that laryngealised sounds and ejectives strongly attract each other. The other two show equally strong positive associations between laryngealised sounds and glottal stops, and between ejective sounds and glottal stops. These results can be explained on the view that all three types of sounds share a feature such as [constricted glottis].

It would be natural to ask whether the patterns involving laryngealised sounds might be due just to obstruents alone, or just to sonorants alone, due to a 'subset effect' of the type discussed in \$2.5.2. To answer this question, separate tests were run for laryngealised obstruents and sonorants. Results are shown in Table XI.

\begin{tabular}{|l|r|r|c|c|c|}
\hline comparison & $\exp$ & obs & association & $\chi^{2}$ & \multicolumn{1}{|c|}{} \\
\hline LAR SON $v s . ?$ & 12 & 24 & positive & $24 \cdot 544$ & $\mathrm{p}<0 \cdot 0001$ \\
LAR SON $v s$. EJECT & 4 & 15 & positive & $37 \cdot 248$ & $\mathrm{p}<0 \cdot 0001$ \\
LAR OBS $v s$. P & 13 & 24 & positive & $17 \cdot 111$ & $\mathrm{p}<0 \cdot 0001$ \\
LAR OBS $v$ s. EJECT & 4 & 7 & positive & $1 \cdot 445$ & n.s. \\
LAR SON vs. LAR OBS & 2 & 10 & positive & $41 \cdot 424$ & $\mathrm{p}<0 \cdot 0001$ \\
\hline
\end{tabular}

Table XI

Comparison of laryngealised sonorants and obstruents with glottal stops and ejectives (rows 1-4) and with each other (row 5). 


\section{G. N. Clements}

This table shows that all associations remain positive; all but one are still highly significant. ${ }^{15}$ These results confirm that both laryngealised sonorants and laryngealised obstruents bear the feature [constricted glottis].

To summarise, the comparisons examined in this section support the characterisation of all laryngealised and glottalised sounds by a single feature, [constricted glottis], shared also with glottal stops. As in the case of the aspirated sounds discussed in the previous sections, these various sounds make use of different articulatory configurations and timing relations. The fact that they pattern together in feature-economy effects provides more evidence that feature economy applies to phonological features rather than to finer-grained phonetic categories.

\subsection{Implosives}

Implosives have long posed a thorny problem for feature analysis. It has widely been assumed, following the influential study of Catford (1939), that implosives are produced with a glottalic airstream mechanism and constitute a variety of glottalised sound. This analysis underlies most subsequent discussions of implosives and has motivated the use of features like [constricted glottis] to characterise implosives. However, as Ladefoged \& Maddieson (1996) have pointed out, glottal constriction is not a regular property of all implosives. Only voiceless (i.e. preglottalised) and laryngealised implosives actually involve any significant amount of glottal constriction. Plain voiced implosives, a very common type, involve modal voicing similar to that found in ordinary voiced stops, and contrast with voiceless (preglottalised) implosives in languages such as Owere Igbo, Ngiti, Lendu and Seereer-Siin. A further problem with the traditional view is that larynx lowering, often taken as a diagnostic for the presence of the glottalic airstream mechanism, has been found to characterise voiced pulmonic stops in languages such as French and English (see Ewan \& Krones 1974, Bell-Berti 1975 and much subsequent work). Given these problems, the feature analysis of implosives remains unclear.

In view of such problems, Clements \& Osu (2002) have proposed that implosives (as well as other types of non-explosive stops) differ from explosive stops in bearing the feature [-obstruent], defined as the absence of positive air pressure behind the oral closure (Stevens 1983, Halle 1992). Implosives fit this definition very well, as they are typically produced with implosion, which requires negative oral air pressure at the moment of release. Clements \& Osu show that such an analysis provides an improved account of the phonetic and phonological properties of all types of implosives. In this view, only laryngealised and voiceless implosives bear the feature [constricted glottis].

15 The fact that the fourth comparison fails to reach significance is due both to the fact that the trend is somewhat weaker than most of the others and to the smaller overall numbers involved. 
Let us compare the two approaches from the perspective of feature economy. We have just seen that glottal constriction creates strong feature-economy effects. If all implosives bore the feature [constricted glottis], we would expect them to show a strong positive association with other glottal sounds (glottal stops, laryngealised sounds and ejectives).

Results of the comparisons are shown in Table XII.

\begin{tabular}{|l|r|r|c|c|c|}
\hline comparison & exp & obs & association & $\chi^{2}$ & \multicolumn{1}{c}{} \\
\hline IMP vs. P & 25 & 24 & negative & $0 \cdot 164$ & n.s. \\
IMP vs. LAR & 5 & 5 & none & - & n.s. \\
IMP $v$ s. EJECT & 8 & 14 & positive & $5 \cdot 726$ & $\mathrm{p}<0.05$ \\
\hline
\end{tabular}

Table XII

Comparison of implosives with glottal stops, laryngealised sounds and ejectives.

The first two comparisons show no positive association between implosives and either glottal stops or laryngealised sounds. These results are unexpected under the [constricted glottis] hypothesis. In contrast, they are just what we would expect under the proposal of Clements \& Osu (2002), if we assume that the proportion of laryngealised and voiceless implosives within the subsample of languages having glottal stops and laryngealised sounds is about the same as it is in the sample as a whole.

However, the third comparison shows a weakly significant positive association between implosives and ejectives. How can we interpret this result?

It was just pointed out that the class of implosives includes both modally voiced sounds and laryngealised (including preglottalised) sounds. In the descriptive literature upon which UPSID is based, these two categories of implosives are not consistently distinguished. ${ }^{16}$ For this reason, UPSID provides no separate category for laryngealised implosives (see Maddieson 1984: 99). As a result, it is usually not possible to tell by inspection of the inventories whether a given implosive is laryngealised, or whether a given laryngealised stop is implosive.

In many cases, however, the sounds listed as implosives are known to be laryngealised. Consider the case of Hausa, listed with the two implosives $/ 6 \mathrm{~d} /$. I show the full set of Hausa stops in (15), following Schuh \& Yalwa (1999). ${ }^{17}$ As this table shows, Hausa has three series of stops, voiceless, voiced and glottalised. Of the latter, some are realised as ejectives and others as laryngealised implosives, according to their place of articulation.

16 Concerning Chadic languages, in which implosives and glottalised sounds are well represented, Paul Newman informs me: 'for most languages that have phonemic "implosives", the phonetic descriptions are suspect, i.e., whatever the author says, you can't be confident that the language has "true implosives" as opposed to “laryngealised" sounds' (personal communication, 2003).

17 I have added the glottalisation diacritic where appropriate (see the following discussion). 
(15) Hausa stops ( $\mathrm{C}=$ laryngealised sounds; $\mathrm{C}^{\prime}=$ ejectives $)$

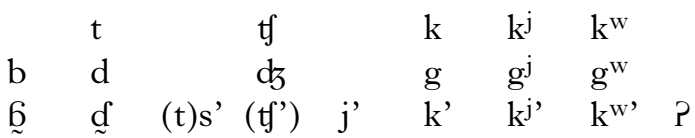

That the two implosives in this chart are laryngealised is not a matter of doubt. In his phonetic study of West African languages, Ladefoged found: 'these sounds may be incidentally implosives on some occasions, but they are always distinguished from their voiced counterparts by being laryngealised' (1968: 16). In a more recent instrumental study, Lindsey et al. (1992) found that the implosives are typically laryngealised, and sometimes even fully glottalised, i.e. produced with the same waveform patterns as the glottal stop. Ladefoged \& Maddieson (1996) have reviewed other studies of Hausa supporting the same conclusions. There is therefore no doubt that the Hausa implosives are laryngealised, in spite of not having been explicitly coded as such in UPSID.

Our hypothesis, then, is that many of the languages listed with both implosives and ejectives in UPSID actually have laryngealised or glottalised implosives, and that it is the presence of glottal constriction in these sounds that accounts for their association with ejectives in Table XII. To test this hypothesis, the fourteen languages in question were rechecked against primary sources, including many descriptions more recent or more complete than those that were used for the original UPSID coding. These languages are given in (16).

$\begin{array}{ll}\text { Afro-Asiatic } & \text { Hausa, Kotoko, Dahalo, Iraqw, Kullo, Hamer } \\ \text { Nilo-Saharan } & \text { Ik, Berta, Koma } \\ \text { Niger-Congo } & \text { Zulu } \\ \text { North American } & \text { Maidu, Mazahua, Jacaltec } \\ \text { South American } & \text { Southern Nambiquara }\end{array}$

We have already discussed Hausa. Of the remaining languages, at least three turn out to have laryngealised or glottalised implosives as well.

Dahalo (or Sanye), a Cushitic language of Kenya with an unusually large consonant inventory, has minimal contrasts between implosives, modally voiced stops and ejectives. Tosco (1991: 4-5) states that the implosives are preglottalised, differing from ejectives in the timing of the release of the glottal and oral occlusions.

Southern Nambiquara (or Nambikuára), a Macro-Tucanian language of Brazil, has plain, aspirated and glottalised voiceless stops. According to Price (1976), the glottalised stops /p' t'/ have preglottalised implosives [' 6 ' $d$ ] among their allophones. There are no other implosives. (It is unclear why these two sounds were coded as separate phonemes in UPSID-92.)

Jacaltec, a Mayan language of Guatemala, has two series of stops, aspirated and glottalised (Day 1973, Craig 1977). ${ }^{18}$ As in Southern Nambiquara,

18 Voiced stops also occur in loanwords from Spanish. 
implosives are variants of glottalised stops. Day states that the glottalised bilabial and uvular stops are exploded before juncture, but are elsewhere either (i) exploded, (ii) imploded or (iii) made with simultaneous glottal and oral closure and no apparent implosion or explosion, with the imploded allophones more common.

Thus in at least four of the fourteen languages in (16), the implosives prove to be glottalised. Furthermore, in at least two others, the existence of any sort of implosive is in doubt.

Iraqw, a Cushitic language of Tanzania, is listed in UPSID-92 with the implosives /6 d/. UPSID's source is Whiteley (1958: 7), who writes: 'the imploded forms occur rarely, and almost always in the 2 nd person shape of the radical'. The implosives are omitted in the more recent description by Mous (1993), who informs me that he does not hear them in the forms cited by Whiteley (personal communication, 2003).

In Zulu there is similar doubt concerning the segment described as implosive /6/. UPSID's classification of this sound is based on descriptions dating from the early years of the twentieth century, when /6/ contrasted with voiced /b/ (Doke 1963 [1927]). ${ }^{19}$ The full plosive system (excluding affricates) at this earlier stage is shown in (17a).

\section{(17) Two stages in the realisation of Zulu plosives}

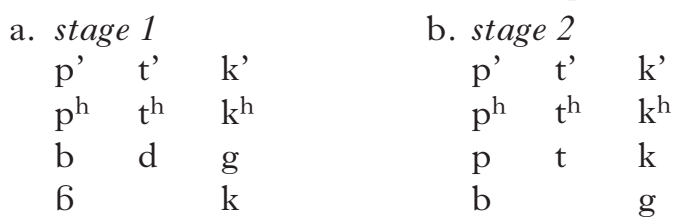

At a later time the voiced plosives $/ \mathrm{b} \mathrm{d} \mathrm{g} /$ became devoiced, and the somewhat marginal phoneme $/ \mathrm{k} /$, largely restricted to affixes, became voiced, at least intervocalically. Subsequently, by an apparent pull-chain effect, $/ 6 /$ shifted to $/ \mathrm{b} /$, giving rise to the modern system shown in $(17 \mathrm{~b})$ as stage 2. (Corresponding sounds have the same place in both charts.) An intermediate stage in this transition was documented by Louw (1962), who found that the formerly voiced stops had partially devoiced, while /6/ still remained implosive.

The non-implosive nature of modern / $b /$ has been confirmed in recent phonetic studies of Zulu. Reporting on an instrumental study of tone depression in Zulu, Traill et al. (1987) write: 'If /b/ is an implosive, it should not lower the tone. Yet it does in all our subjects. The pharyngeal pressure records leave no doubt as to why this is so: $/ \mathrm{b} /$ is not an implosive in our data'. Traill et al. also confirmed the devoicing of the formerly voiced stops. ${ }^{20}$ These findings, based on four speakers, were confirmed in an

19 Doke is a phonetically trained observer who based his descriptions on instrumental studies.

20 In modern Zulu the formerly voiced stops now realised as [p $\mathrm{t} k$ ] continue to function as phonological tone depressors, while the former implosive now realised as $[\mathrm{b}]$ and the formerly voiceless stop now realised as [g] continue to function as 
independent study of two other speakers by Giannini et al. (1988). In recent work, Best et al. (2001) have provided further acoustic data on the production of stage $2 / \mathrm{p} /$ and $/ \mathrm{b} /$ by a single speaker. Although they retain Doke's notation and phonetic classification, their findings are largely consistent with those of the two earlier studies; in particular, $/ \mathrm{p} /$ is described as 'not prevoiced', i.e. unvoiced, and /b/ is found to have a strong burst, as one would expect in an explosive stop.

Thus, there is converging evidence that formerly implosive /6/ is now produced as explosive /b/ in Zulu. Moreover, it seems unlikely that this sound ever bore a feature of glottal constriction historically, since if it did we would have expected the ejectives to support it and inhibit any tendency for it to shift into the plain voiced series.

In the remaining languages shown in (16), existing descriptions are too sketchy to allow any firm conclusion on the phonetic realisation of implosives. However, even in the unlikely event that all these implosives turned out to be non-laryngealised, there would still be only eight genuine cases of languages containing non-laryngealised implosives and ejectives. If we now recalculate the frequencies on this basis, the last row of Table $\mathrm{XII}$ is revised as follows:

\begin{tabular}{|l|c|c|c|c|l|}
\hline comparison & $\exp$ & obs & association & $\chi^{2}$ & \\
\hline IMP (modally voiced) vs. EJECT & 7 & 8 & positive & $0 \cdot 120$ & n.s. \\
\hline
\end{tabular}

\section{Table XIII}

Last row of Table XII revised to include only modally voiced implosives.

The association is now only barely positive and far from significant.

To conclude, we have found no tendency for ordinary implosives to associate with any type of glottalised or laryngealised sound, or with glottal stops, in sound inventories. This result contradicts the long-standing view that all implosives are glottalised sounds, but is consistent with the analysis of Clements \& Osu (2002), according to which implosives are [-obstruent] stops, realised with or without glottalisation, according to the language. ${ }^{21}$

\section{Feature-economy effects on redundant features}

We now ask whether feature economy applies only to distinctive features, as has been traditionally assumed, or to some types of redundant features as well.

non-depressors, creating an 'unnatural' match between consonant types and tones at the phonological level. The lowering effect of modern /b/observed by Traill and his collaborators is phonetic, not phonological (1987: 263-264).

21 We cannot use feature economy to test this analysis; since (nearly) all languages have non-obstruent consonants in the first place, there is no basis of comparison in languages lacking such sounds. See, however, Clements \& Osu (2002) for a review of other types of phonological evidence supporting this analysis. 
Features are distinctive or redundant at two levels: (i) the system as a whole, and (ii) the segment. We will say that a feature is distinctive at the system level, or GLOBALLY distinctive, if it crucially distinguishes at least one pair of sounds in the system; otherwise it is globally redundant. For example, the feature [+voiced] is globally distinctive in any system containing either subsystem in (18), since it crucially distinguishes T from D. A feature is distinctive in a segment, or LOCALLY distinctive, if it crucially distinguishes that segment from another; otherwise it is locally redundant in that segment. For example, [+voiced] is locally distinctive in $\mathrm{D}$ in both subsystems in (18), and it is locally distinctive in $\mathrm{B}$ in subsystem $A$, but it is locally redundant in B in subsystem $B$.

\begin{tabular}{|c|c|}
\hline subsyste & subsystem $B$ \\
\hline P $\quad \mathrm{T}$ & $\mathrm{T}$ \\
\hline B D & B D \\
\hline
\end{tabular}

The question now arises whether feature economy applies to features which are globally distinctive but locally redundant, such as [+voiced] in $\mathrm{B}$ in subsystem $B$ in (18). As a basis for answering this question, let us compare the more complete subsystems $C$ and $D$ shown in (19):

$\begin{array}{cll} & \text { subsystem C } & \text { subsystem } D \\ & \mathrm{~T} & \mathrm{~T} \\ & \mathrm{D} & \mathrm{B} \mathrm{D} \\ \mathrm{M} \mathrm{N} & \mathrm{M} \mathrm{N} \\ \text { features } & {[\text { labial], [voiced], [sonorant] }} & {[\text { labial], [voiced], [sonorant] }} \\ E(S / F) & 1.33 & 1.67\end{array}$

The features [labial], [voiced] and [sonorant] are globally distinctive in all three systems, since each distinguishes at least one pair of sounds:

$\begin{array}{ll}\text { [labial] } & \mathrm{M} v s . \mathrm{N} \\ \text { [voiced] } & \mathrm{T} v s . \mathrm{D} \\ \text { [sonorant] } & \mathrm{D} v s . \mathrm{N}\end{array}$

However, as shown on the bottom line in (19), subsystem $D$ has a higher economy index than subsystem $C$. This is due to the presence of $\mathrm{B}$, in which voicing is redundant. We see, then, that in such cases segments bearing locally redundant values of globally distinctive features increase the economy of a system. Feature economy predicts such segments to be favoured.

To test this prediction, we may examine the frequencies of $\mathrm{B}, \mathrm{D}$ and $\mathrm{G}$ in 'skewed' systems - systems with gaps - which lack P, but contain a labial vs. non-labial contrast elsewhere in the consonant system, as in subsystem $D$ of (19). There are 44 such languages in the UPSID sample. Feature economy predicts that B should be more frequent in languages 
with $\mathrm{D}$ and/or $\mathrm{G}$ than would be expected on the assumption that their frequencies were independent (i.e. that no feature-economy effects are involved). That is, observed values should be significantly higher than expected values.

Results of the comparisons are shown in Table XIV:

\begin{tabular}{|l|c|c|c|c|c|}
\hline comparison & $\exp$ & obs & association & $\chi^{2}$ & \multicolumn{1}{|c}{} \\
\cline { 1 - 4 } B vs. D & 35 & 38 & positive & 11.423 & $\mathrm{p}<0.001$ \\
B vs. G & 34 & 36 & positive & 6.334 & $\mathrm{p}<0.05$ \\
\hline
\end{tabular}

\section{Table XIV}

Comparison of the frequency of $\mathrm{B}$ with the frequencies of $\mathrm{D}$ and $\mathrm{G}$ in systems lacking $\mathrm{P}$ but having some other labial vs. non-labial contrast $(\mathrm{N}=44)$.

These results bear out the prediction. Both comparisons show a significant positive trend. However, both $\chi^{2}$ values are much lower than those for the similar comparisons in Table IV, which ranged over the full set of 451 languages (there $\left.\chi^{2}(\mathrm{~B} v s . \mathrm{D})=328 \cdot 749, \chi^{2}(\mathrm{~B} v s . \mathrm{G})=266 \cdot 221\right)$. This difference is due both to the proportionately smaller ratio of observed over expected values in Table XIV, and to the smaller sample size (44 vs. 451 languages). It is worth pointing out that if the same proportions held in a sample ten times the size (i.e. one containing 440 languages, making it comparable to the sample in Table IV), these comparisons, too, would reach significance at the 0.0001 level.

Let us look for a comparison involving larger numbers. For this purpose we may consider systems containing nasals which lack oral counterparts. The subsystems in (21) have the same structure as those in (19), since the order of rows is irrelevant. [labial] is globally distinctive in both systems, as it distinguishes $\mathrm{P}$ and $\mathrm{T}$, and so is [+nasal], which distinguishes $\mathrm{N}$ and $\mathrm{R}$ (standing for any oral coronal approximant consonant). However, [+nasal] is locally redundant in $\mathrm{M}$ in subsystem $B$, as it lacks a corresponding labial approximant consonant, $[\beta]$ or $[\mathrm{v}]$.

$\begin{array}{lll} & \text { subsystem } A & \text { subsystem } B \\ & \mathrm{P} & \mathrm{P} \mathrm{T} \\ & \mathrm{N} & \mathrm{M} \mathrm{N} \\ \mathrm{R} & \mathrm{R} \\ \text { features } & \text { [labial], [sonorant], [nasal] } & \text { [labial], [sonorant], [nasal] } \\ E(S / F) & 1.33 & 1.67\end{array}$

Independent testing shows that $\mathrm{M}$ and $\mathrm{N}$ exhibit feature-economy effects in the sample as a whole $(p<0.0001)$. Do they also show feature-economy 
effects in subsystem $B$, in which nasality is locally redundant in M? As in the previous case, feature economy predicts that they should.

To test this prediction, the frequency of $\mathrm{M}$ was compared to those of $\mathrm{N}$ and NG (representing any dorsal nasal) in languages lacking labial approximants (defined as non-nasal labial sonorant consonants), but containing labial, coronal and dorsal obstruents. There are 404 such languages in the sample. The prediction is once again that observed values should be significantly higher than expected values.

Results of the comparison are shown in Table XV.

\begin{tabular}{|l|l|l|c|r|c|}
\hline comparison & exp & obs & association & $\chi^{2}$ & \multicolumn{1}{|c}{} \\
\hline M vs. N & 367 & 381 & positive & $248 \cdot 319$ & $\mathrm{p}<0 \cdot 0001$ \\
M vs. NG & 202 & 212 & positive & $20 \cdot 442$ & $\mathrm{p}<0 \cdot 0001$ \\
\hline
\end{tabular}

Table XV

Comparison of the frequency of $\mathrm{M}$ with the frequencies of $\mathrm{N}$ and NG in systems lacking labial approximants but containing labial, coronal and dorsal obstruents $(\mathrm{N}=404)$.

We see that $\mathrm{M}$ associates positively with both $\mathrm{N}$ and NG at the $0 \cdot 0001$ level of significance. Thus feature economy applies, as predicted, to [+nasal], even in sounds in which this feature is redundant. ${ }^{22}$

We conclude that locally redundant values of globally distinctive features participate in feature-economy patterns. However, the effect of feature economy on redundant features does not stop here. Contextually redundant feature values are often introduced into phonological systems by context-sensitive processes. Such processes typically apply to full natural classes of sounds, and the non-distinctive variants they create may extend existing features to new classes of sounds. Examples come readily to mind. For instance, though Nepali does not have phonemic voiceless sonorants in its system (see (1)), it acquires them as the result of a process that devoices (i.e. aspirates) sonorants after voiceless aspirated stops (Pokharel 1989). All sonorants are affected, as shown by the examples in (22):

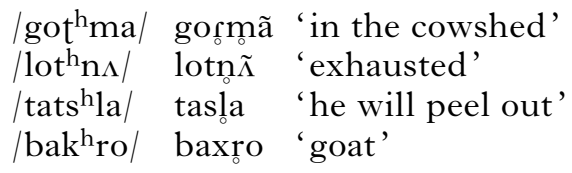

22 Comparison of Tables XIV and XV shows the importance of running subset tests on large numbers of languages. The proportion of observed over expected languages is almost identical in the two comparisons (in Table XIV they are 1.06 and 1.06 , and in Table XV they are 1.04 and 1.05 , respectively), but the significance levels are very different, due to the difference in sample sizes. 
This pattern, too, counts as an instance of feature economy, since in the surface forms [spread glottis] is extended to sonorants. New sounds are created with existing features, increasing the ratio $S / F .^{23}$

Redundant values created in this way may subsequently create a new series of distinctive sounds. A further example will illustrate. In earlier stages of Kikuyu, a Bantu language spoken in Kenya, voiceless stops, voiced fricatives and liquids acquired fully voiced stop allophones after nasals (Armstrong 1940). This process created regular alternations, as shown in the first two columns of (23). At this stage, voicing was contextually redundant in postnasal stops. For most contemporary speakers, however, the nasal that originally triggered the voicing has completely disappeared, leaving a new series of voiced stops at each place of articulation, as shown in the third column.

$\begin{array}{llll}\text { singular } & \text { plural (earlier) } & \text { plural (later) } & \\ \text { ro-ßaru } & \text { m-baru } & \text { baru } & \text { 'rib' } \\ \text { ro-tumś } & \text { n-dumś } & \text { dumś } & \text { 'seam' } \\ \text { ro-raacio } & \text { n-daacio } & \text { daacis } & \text { 'bride-wealth' } \\ \text { ro-cuðe } & \text { n-juðe } & \text { juðe } & \text { 'backbone' } \\ \text { ro-koojgo } & \text { n-goongo } & \text { googo } & \text { 'dust' } \\ \text { ro-yiri } & \text { n-giri } & \text { giri } & \text { 'fence' }\end{array}$

The new series increases the overall system economy since one new feature has generated four new phonemes, $/ \mathrm{b} \mathrm{d} \mathrm{Jg} /$. Evolutions such as this constitute a major historical source of feature economy in sound systems.

To summarise, this section has shown that feature economy applies to locally redundant values of distinctive features. Moreover, phonological processes introducing new feature combinations can create non-distinctive variants in an entire series of sounds, which may become distinctive as a result of later evolution. Thus feature economy is not restricted to the phoneme level, as has often been thought, but applies as well to the typically larger inventory of sounds occurring in surface phonological representations.

\section{Feature economy or gesture economy?}

Given these results, a new question arises. If feature economy applies to surface representations, as we have just seen, might it not actually apply at

23 It is [spread glottis] rather than [-voiced] that spreads in Nepali, since plain voiceless stops do not trigger devoicing. The phonetic reason for this is that glottal opening is aligned with the stop release only in aspirated sounds, where it creates a devoiced interval following the stop burst. This may explain why only aspirated sounds seem to have the ability to devoice following sonorants. Another example can be seen in English, where aspiration 'bleeds' from the stop into the liquid in words like trip, causing [r] to be partially devoiced, but does not do so in strip, in which [t] is unaspirated. In Nepali, the phonetic tendency toward devoicing has gone further: sonorants are fully devoiced after aspirated stops, and according to Pokharel, devoicing continues into the beginning of the next vowel. 
the phonetic rather than the phonological level? In this case might we better speak of 'gesture economy' than 'feature economy'? Such a view would hold that languages economise not features as such, but the ARTICULATORY GESTURES used to construct the units of their sound inventories. In the Kikuyu case, for example, what would be economised is not the feature [+voiced], but the articulatory gesture of voicing.

This section considers this view and compares its predictions with those of feature economy. In feature theory as it is understood here, features are defined in both the articulatory and acoustic/perceptual domains (Halle 1983). Articulatory definitions are typically given in terms of location or degree of constriction, rather than articulatory movements as such (Stevens 1989, Carré \& Mrayati 1990, Clements \& Hume 1995). ${ }^{24}$ In this view, for example, [labial] sounds are defined as those which involve any constriction at the lips (corresponding to distinctive region $\mathrm{A}$ in the Carré \& Mrayati model), with no further specification as to more specific configurations such as 'bilabial' or 'labiodental'. Labial sounds thus represent a FAMILY of finer-grained articulatory types, including bilabials and the several different types of labiodentals identified by Ladefoged \& Maddieson (1996). Feature-economy effects involving [labial] are expected to affect all members of this family.

What are the predictions of gesture economy? In one influential articulatory model (Browman \& Goldstein 1989), gestures are defined in terms of the quantitatively specified parameters of a set of equations defining trajectories of the articulators - lips, tongue tip (TT) and tongue body (TB) - over time. These articulator sets include specifications for constriction degree, constriction location, constriction shape and stiffness. In this approach, two gestures are different if they differ in any parameter specification. Thus, for example, labiodental [f], which is partly defined in terms of the oral gesture LIPS[critical dental], involves a different gesture from bilabial [p], defined as LIPS[closed labial]. It also differs from alveolar [s], which is specified as TT[critical alveolar].

One way of comparing the two approaches, then, is to examine possible interactions between bilabial and labiodental sounds, and between fricatives at different places of articulation. Feature economy predicts mutual attraction effects in all cases, while gesture economy does not.

As a test case, let us examine the frequencies of labiodental fricatives [f] and coronal fricatives $\mathrm{S}$ in languages also having bilabial consonants, but in which [f] is the unique labiodental consonant. Feature economy predicts that [f] should be more frequent in that subset of languages which also have coronal fricatives, due to the fact that the features [labial] and [+continuant] are independently present in the system. Thus, for example, the addition of [f] to subsystem $A$ in (24) increases its economy from $1 \cdot 50$ to $2 \cdot 00$, as it adds no new feature.

${ }^{24}$ Not all features are defined in terms of constrictions. For example, [+obstruent], as noted above, is defined in terms of air pressure, and the feature [+strident] seems most simply defined in terms of the presence of an intense high-frequency noise component. 


$$
\begin{array}{ll}
\text { subsystem } A & \text { subsystem } B \\
\mathrm{p} \mathrm{t} & \mathrm{p} \mathrm{t} \\
\mathrm{s} & \mathrm{f} \mathrm{s}
\end{array}
$$

features [labial], [continuant] [labial], [continuant]

$E(S / F) \quad 1.50 \quad 2.00$

Gesture economy, on the other hand, predicts no interaction in such cases, since bilabial and labiodental sounds involve different gestures. The addition of [f] to a system with [p] and [s] adds a new sound and a new gesture, maintaining its economy index, as shown in (25).

$\begin{array}{lll} & \text { subsystem } A & \text { subsystem } B \\ & \mathrm{p} \mathrm{t} & \mathrm{p} \mathrm{t} \\ \text { gestures } & \mathrm{s} & \mathrm{f} \mathrm{s} \\ & \text { LIPS[closed labial] } & \text { LIPS[closed labial] } \\ & \text { TT[closed alveolar] } & \text { TT[closed alveolar] } \\ & \text { TT[critical alveolar] } & \text { TT[critical alveolar] } \\ & & \text { LIPS[critical dental] } \\ E(S / G) & 1.00 & 1.00\end{array}$

Table XVI shows the results of comparing the frequencies of labiodental [f] and $\mathrm{S}$ in languages having bilabial consonants but no other labiodental consonants. It confirms the prediction of feature economy: [f] is significantly more frequent in languages having some voiceless coronal fricative $\mathrm{S}^{25}$

\begin{tabular}{|l|c|c|c|c|c|}
\hline comparison & $\exp$ & obs & association & $\chi^{2}$ & \multicolumn{1}{|c}{} \\
\cline { 1 - 4 } [f] vs. S & 68 & 79 & positive & $16 \cdot 001$ & $\mathrm{p}<0.0001$ \\
\hline
\end{tabular}

Table XVI

Comparison of the frequencies of voiceless labiodental fricatives [f] and voiceless coronal fricatives $\mathrm{S}$ in languages containing bilabial consonants but no other labiodental consonants $(\mathrm{N}=267)$.

The problem for gesture economy is that [p], [f] and [s] all involve different gestures, and should not be expected to interact. This problem is not tied to the particular gesture model that we have chosen, since other models give similar results. Suppose, for example, that we define a gesture as a 'typical movement trajectory for a given articulatory subsystem in

25 The gesture underlying voicelessness cannot be regarded as responsible for economy effects here since voicelessness does not generally define cross-category economy effects. For example, voiceless labial stops $\mathrm{P}$ and fricatives $\mathrm{F}$ exhibit negative attraction: languages with one tend not to have the other $\left(\chi^{2}=6 \cdot 215\right.$, $\mathrm{p}<0 \cdot 05)$. It is suggested in the final discussion that feature-economy effects only apply to marked feature values. 
realising a given phonetic contrast, bearing in mind the initial conditions for the start of the gesture, anticipation of the following context, and any competing demands of any other simultaneously specified aspects of the phonetic element of which the gesture is a component' (Maddieson 1995: 574). If 'articulatory subsystems' are understood roughly as articulator sets in the sense of Browman \& Goldstein, then the same problem arises: $[\mathrm{p}],[\mathrm{f}]$ and $[\mathrm{s}]$ are implemented by different articulatory subsystems and so involve different gestures.

The notion 'gesture' differs from 'feature', then, in being overly specific; it cannot cover the full range of economy effects observed in sound systems. While we have discussed place and manner features here, similar problems are raised by laryngeal features. Consider the various types of aspirated and laryngealised sounds examined in $\S 4$. These sounds embrace a variety of different glottal configurations. For example, voiceless aspirated stops are characterised by a maximally open glottis, and voiced aspirated stops by a glottis which is sufficiently adducted so as to permit voicing while still permitting a high rate of airflow. These differences are under speaker control and cannot be regarded as variant implementations of the same gesture, yet we observe strong economy effects between voiced and voiceless aspirated stops.

This does not mean that the notion of gesture economy is useless, however. Gesture economy may make correct predictions at the phonetic level in claiming that fully redundant features tend to be implemented in terms of uniform articulatory configurations within given classes of sounds. Consider the distinction between dental and alveolar plosives (non-sibilants). 412 UPSID languages lack a contrast between these two places of articulation. In these languages, the dental/alveolar distinction is globally redundant. However, UPSID encodes the dental/alveolar distinction when it is recorded in source descriptions, even in languages which have only one series or the other. Table XVII shows that in the 412 languages which do not have contrasts between these two types of sounds, dentals strongly favour dentals and alveolars strongly favour alveolars.

\begin{tabular}{|l|r|r|c|c|c|}
\hline comparison & exp & obs & association & $\chi^{2}$ & \multicolumn{1}{|c|}{} \\
\hline $\mathrm{t}_{\text {dent }}$ vs. $\mathrm{d}_{\text {dent }}$ & 14 & 66 & positive & $286 \cdot 197$ & $\mathrm{p}<0 \cdot 0001$ \\
$\mathrm{t}_{\text {alv }}$ vs. $\mathrm{d}_{\text {alv }}$ & 46 & 111 & positive & $211 \cdot 344$ & $\mathrm{p}<0 \cdot 0001$ \\
$\mathrm{t}_{\text {dent }}$ vs. $\mathrm{d}_{\text {alv }}$ & 24 & 2 & negative & $36 \cdot 335$ & $\mathrm{p}<0 \cdot 0001$ \\
$\mathrm{t}_{\text {alv }}$ vs. $\mathrm{d}_{\text {dent }}$ & 27 & 1 & negative & $48 \cdot 901$ & $\mathrm{p}<0 \cdot 0001$ \\
\hline
\end{tabular}

\section{Table XVII}

Comparison of the frequencies of dental and alveolar plosives in languages in which these sounds do not contrast $(\mathrm{N}=412)$.

This pattern is not an effect of feature economy, but of gesture economy. Feature economy is not increased by generalising dental or alveolar place 
to other stops, since no new sounds are being added to the system (existing sounds are being more narrowly specified). ${ }^{26}$ Rather it is an effect of gesture economy, which requires anterior stops to be specified uniformly as either TT[closed alveolar] or TT[closed dental] at the phonetic level. In this example, gestures, not features, are being economised.

To take another example, many languages have only one series of stop consonants. In such cases, stops are normally realised as voiceless. In a less frequent pattern, represented by six languages in UPSID-92, all stops are voiced. Again, this is not a case of feature economy, since a globally redundant feature like [+voiced] does not increase system economy. However, it can be regarded as an instance of gesture economy.

As Keating has observed (2003), such 'articulatory uniformity' may operate at the level of individual speakers as well as languages. In several well-studied cases, different speakers of the same dialect of a language have been found to implement the same speech sound with different gestures (consider the many types of $/ \mathrm{r} /$-sounds in standard varieties of English, or the different realisations of $/ \mathrm{t} \mathrm{d} \mathrm{n} \mathrm{l} /$ in French observed by Dart 1998). In such cases, one cannot speak of gesture economy at the level of the language as a whole, though individual speakers may be consistent in their articulations. Keating's examples involved VOT differences in the realisation of initial / $\mathrm{b} \mathrm{d} \mathrm{g/} \mathrm{in} \mathrm{English,} \mathrm{but} \mathrm{one}$ could expect a similar uniformity involving place of articulation. For example, though speakers of French vary between dental and alveolar articulations of $/ \mathrm{t} \mathrm{d} /$ (most preferring dental contact), a given speaker is likely to be consistent, producing them both either as dental or alveolar. Here again one can speak of gesture economy, though only at the individual level.

Gesture economy seems therefore best viewed as a principle of phonetic implementation, specifying redundant properties, and thus operating within distinctive feature boundaries rather than across them. As such, it is not a competitor to feature economy, but complementary to it. This does not mean that the two principles never interact. Phonology can be seen as a grammaticalisation of the quantitative patterns determined by phonetic constraints, and feature economy can be viewed, in some instances, as a grammaticalisation of gesture-economy effects operating at the more abstract feature level. Thus, non-distinctive allophonic patterns introduced in particular contexts may generalise over classes of sounds due to gesture economy, and if these patterns subsequently become grammatically or lexically relevant (as in the example of stop voicing in Kikuyu), a pattern

${ }^{26}$ In the feature system assumed here, the dental/alveolar distinction does not correspond to any distinctive feature. Where both dental and alveolar sounds are found, they very frequently reflect a more basic laminal vs. apical articulation which can be encoded in terms of the traditional feature [ \pm distributed], or in terms of a distinction in stridency, such as between dental $[\theta]$ and alveolar [s]. The dental/alveolar distinction may not be minimally distinctive in any language (for further discussion see Ladefoged \& Maddieson 1996: 20-21, Hall 1997: 42, Clements 1999: 280). 
that was originally determined by gesture economy will have become transformed into a pattern of feature economy.

\section{Summary and discussion}

This paper has argued that feature economy constitutes one of the basic principles governing the organisation of sound systems. It has outlined a method for studying feature-economy effects and has shown how this method can be applied to the study of phoneme inventories. We have seen that feature economy not only provides strong evidence for the role of features in general, but constitutes a criterion for choosing between competing analyses of speech sounds. We have also seen that feature economy affects not only distinctive features, but locally redundant feature values as well, and that historical change may increase the economy of a sound system by introducing new, non-distinctive sound classes, which may eventually become phonemicised themselves. Feature-economy effects cannot be reduced to purely phonetic principles, but a parallel principle of gesture economy (or articulatory uniformity) operates at the level of phonetic realisation.

Most of the discussion in this paper has concerned consonants, but it is natural to ask whether feature economy applies to vowels as well. It seems likely that the answer is 'yes'. It has long been observed that vowel systems are typically symmetrical. As Trubetzkoy noted in a letter to Jakobson in 1928, on the basis of an examination of 46 vowel systems:

I have never yet run across a system without a symmetrical vowel system. All systems conform to a small number of types and can always be represented by symmetrical schemes (triangles, parallel rows, etc.) (Trubetzkoy 2001: 187).

This generalisation holds, at least as a strong trend, over the much larger vowel inventories that have been collected since then, by Trubetzkoy himself and by others following his lead. For example, Maddieson (1984) notes that most vowel systems in his earlier UPSID survey can be described as triangular. My own preliminary testing has brought to light strong feature-economy effects among vowels in the UPSID-92 database which I hope to report on elsewhere.

A competing principle of vowel-inventory structure is dispersion theory, which predicts that vowels tend to be maximally dispersed in perceptual space (Liljencrants \& Lindblom 1972, Lindblom 1986). Schwartz et al. (1997) have noted that this principle does not fully explain the symmetrical pattern of peripheral vowels, and suggest that it must be reinforced by a feature model in order to explain the 'maximum utilisation of the available distinctive features', another term for feature economy. Boersma (1998) makes a similar point. More recent work in adaptive dispersion theory has tended to constrain the predictions of maximal 
dispersion through the introduction of further principles such as articulatory complexity and focalisation, which tend to counteract the strong predictions of the original theory. ${ }^{27}$

The remainder of this discussion addresses two more general questions: what features are subject to feature economy, and how is feature economy to be explained?

It appears that feature economy applies only to features that are typically active in languages, whether because they are lexically distinctive or because they are activated by phonological processes (as in the Nepali and Kikuyu examples cited earlier). Features that typically fill neither of these functions - those that are fully redundant and phonologically inactive - do not appear to display economy effects in any systematic way. It further appears that only marked values of such features trigger economy effects. Most of the strong economy effects observed here have involved either one-valued features such as [spread glottis] and [constricted glottis], or marked values of binary features such as [+voiced] and [+continuant]. An apparent exception is the economy effects found among unaspirated voiceless stops $\mathrm{P}^{-} \mathrm{T}^{-} \mathrm{K}^{-}$in $\S 3.1$, which lack [spread glottis] and [constricted glottis] and bear the unmarked values of all manner features. However, we are probably not dealing in this case with a true featureeconomy effect. These three consonants are maximally unmarked; none of them requires 'support' from other consonants in the system. We can regard them as present by default. The opposite is true of consonants bearing marked or one-valued features; though such features are generally disfavoured, the presence of one lowers the threshold for admitting others into the system.

How can feature economy be explained? As pointed out earlier, Martinet had originally suggested that feature economy could be motivated in terms of performance factors such as ease of articulation, increased perceptual distinctness and speed of acquisition (Martinet 1968). However, while such factors play a role in accounting for many trends in sound patterning, it is unclear that they shed any light on feature economy. Consider ease of articulation. We have already seen that feature economy cannot be reduced to simple gesture economy; for example, voiceless fricatives show strong economy effects, but the gesture required to guarantee continuous noisy airflow in $\mathrm{S}$ is quite different from that required in $\mathrm{F}$ or $\mathrm{X}$, and it is difficult to see how the mastery of one could facilitate the acquisition of another at the purely motor level. Nor does the generalisation of continuance from $\mathrm{S}$ to $\mathrm{F}$ and $\mathrm{X}$ increase the token frequency of any gesture, or reduce the number of motor routines that must be committed to memory. It also seems unlikely that feature economy increases perceptual distinctness; indeed, it seems to work in the opposite direction. As Ohala has pointed out (1980), the implausible seven-consonant system / $\mathrm{d} \mathrm{k}^{\prime}$ ts $\mathrm{H} \mathrm{m} \mathrm{rl} /$ is well dispersed in perceptual

27 See Clements (2003) for further discussion. 
space, but makes an uneconomical use of features. Feature economy tends to concentrate sounds along a small number of dimensions, which typically reduces the perceptual distance among them, in the absence of further enhancement effects.

It seems more plausible to suggest that feature economy operates at a higher cognitive level at which speech sounds are encoded in terms of relatively abstract elements functioning within a grammatical system. Feature economy in this view reflects a general predisposition to organise linguistic data into a small number of categories and to generalise these categories maximally, consistently with independent constraints on their functioning. From this perspective, feature economy appears to involve the interaction of the same principles of category formation and generalisation that are at work in other areas of grammar.

Even in phonology, economy applies to non-featural categories which cannot be defined in terms of elementary articulatory gestures. For example, $\mathrm{H}$-sounds and glottal stops pattern together strongly in the UPSID database $(p<0 \cdot 0001)$, though they share no articulatory gesture. What they have in common is that both are characterised by the laryngeal node, an abstract category which encodes the ability of laryngeal features to function as a unit in phonological processes. As another example, it is a common observation that languages that have one geminate consonant (or long vowel) tend to have many. But geminate consonants such as $/ \mathrm{pp} /$ and /tt/ share no single articulatory gesture or feature; what they have in common are abstract units of quantity, represented in terms of timing slots or moras. Again, languages that have one consonant cluster, such as $/ \operatorname{tr} /$, tend to have many others of the same type. The fact that phonological rules and constraints apply to natural classes - in which a few features are used to designate large numbers of sounds - can be seen as another manifestation of feature economy.

Outside phonology, economy is evident in many domains of grammar in which categories generalise across linguistic units. This is particularly evident in morphosyntax, where languages that have one formally marked noun class, case, tense, aspect or person/number category, etc. tend to have several. Such categories tend to generalise across all lexical items with which they are semantically compatible; for example, if a language has one noun marked for dual number or ablative case, it is likely to have many. Like phonological features, such categories tend to cross-classify others (e.g. number typically cross-classifies case), while dysfunctional categories (such as number distinctions on mass nouns) tend to be avoided. Word formation, too, exhibits economy in its generalisation of relatively small sets of affixes to large numbers of forms.

Feature economy appears, then, to be a special case of a broader principle of economy which is reflected in other aspects of linguistic organisation as well. It might be expressed as 'maximise $\mathrm{U} / \mathrm{C}$ ', where $\mathrm{U}$ is a set of linguistic units and $\mathrm{C}$ the categories which are used to characterise them. As an abstract cognitively based principle, economy in this broader sense may not be unique to spoken language, and a worthwhile programme of 
research might be to examine its applications in non-spoken language forms and other types of communication systems.

\section{REFERENCES}

Armstrong, Lilias E. (1940). The phonetic and tonal structure of Kikuyu. London: International African Institute. Reprinted 1967, Dawsons of Pall Mall.

Bandhu, C. M., B. M. Dahal, A. Holzhausen \& A. Hale (1971). Nepali segmental phonology. Kirtipur: Tribhuvan University.

Basbøll, Hans (1985). Review of Maddieson (1984). Phonology Yearbook 2. 343-353.

Bell-Berti, Fredericka (1975). Control of pharyngeal cavity size for English voiced and voiceless stops. $\mathcal{F} A S A$ 57. 456-461.

Benguerel, André-Pierre \& Tej K. Bhatia (1980). Hindi stop consonants: an acoustic and fiberscopic study. Phonetica 37. 134-148.

Best, Catherine T., Gerald W. McRoberts \& Elizabeth Goodell (2001). Discrimination of non-native consonant contrasts varying in perceptual assimilation to the listener's native phonological system. $\mathcal{F} A S A$ 109. 775-794.

Boersma, Paul (1998). Functional phonology: formalizing the interactions between articulatory and perceptual drives. PhD thesis, University of Amsterdam. The Hague: Holland Academic Graphics.

Bole-Richard, Rémy (1983). Systématique phonologique et grammaticale d'un parler éwé : le gen-mina du sud-togo et sud-bénin. Paris: L'Harmattan.

Browman, Catherine P. \& Louis Goldstein (1989). Articulatory gestures as phonological units. Phonology 6. 201-251.

Butler, Christopher (1985). Statistics in linguistics. Oxford: Blackwell.

Bybee, Joan (2001). Phonology and language use. Cambridge: Cambridge University Press.

Capo, Hounkpatin C. (1981). Nasality in Gbe: a synchronic interpretation. Studies in African Linguistics 12. 1-43.

Carré, René \& Mohamed Mrayati (1990). Articulatory-acoustic-phonetic relations and modeling, regions and modes. In W. J. Hardcastle \& A. Marchal (eds.) Speech production and speech modelling. Dordrecht: Kluwer. 211-240.

Catford, J. C. (1939). On the classification of stop consonants. Le Maître Phonétique 65. $2-5$.

Chomsky, Noam \& Morris Halle (1968). The sound pattern of English. New York: Harper \& Row.

Clements, G. N. (1985). The geometry of phonological features. Phonology Yearbook 2. 225-252.

Clements, G. N. (1999). Affricates as noncontoured stops. In Osamu Fujimura, Brian D. Joseph \& Bohumil Palek (eds.) Proceedings of LP' 98 : item order in language and speech. Prague: Karolinum Press. 271-299.

Clements, G. N. (2001). Representational economy in constraint-based phonology. In T. Alan Hall (ed.) Distinctive feature theory. Berlin \& New York: Mouton de Gruyter. 71-146.

Clements, G. N. (2003). Feature economy as a phonological universal. In Solé et al. (2003). 371-374.

Clements, G. N. \& Elizabeth Hume (1995). The internal organization of speech sounds. In John Goldsmith (ed.) The handbook of phonological theory. Cambridge, Mass. \& Oxford: Blackwell. 245-306.

Clements, G. N. \& Sylvester Osu (2002). Explosives, implosives and nonexplosives: the linguistic function of air pressure differences in stops. In Carlos Gussenhoven \& Natasha Warner (eds.) Laboratory phonology 7. Berlin \& New York: Mouton de Gruyter. 299-350. 
Craig, Colette Grinevald (1977). The structure of Facaltec. Austin: University of Texas Press.

Dart, Sarah N. (1998). Comparing French and English coronal consonant articulation. FPh 26. 71-94.

Davis, Katharine (1994). Stop voicing in Hindi. FPh 22. 177-193.

Day, Christopher (1973). The Facaltec language. Bloomington: Indiana University.

Dell, François (1985). Les règles et les sons. 2nd revised edn. Paris: Hermann.

Demolin, Didier (1995). The phonetics and phonology of glottalized consonants in Lendu. In Bruce Connell \& Amalia Arvaniti (eds.) Phonology and phonetic evidence: papers in laboratory phonology IV. Cambridge: Cambridge University Press. 368-385.

Dixit, R. Prakash (1989). Glottal gestures in Hindi plosives. FPh 17. 213-237.

Doke, Clement M. (1963) [1927]. Textbook of Zulu grammar. 6th edn. Cape Town: Longmans Southern Africa.

Elbert, Samuel H. \& Mary Kawena Pukui (1979). Hawaiian grammar. Honolulu: University Press of Hawaii.

Ewan, William G. \& Robert Krones (1974). Measuring larynx movement using the thyroumbrometer. $\mathscr{F P h}$ 2. 327-335.

Giannini, Antonella, Massimo Pettorino \& Maddalena Toscano (1988). Some remarks on Zulu stops. Afrikanistische Arbeitspapiere 13. 95-116.

Gordon, Matthew (2001). Linguistic aspects of voice quality with special reference to Athabaskan. In Siri Tuttle \& Gary Holton (eds.) Proceedings of the 2001 Athabaskan Languages Conference. Fairbanks: Alaska Native Langue Center. 163-178.

Grimes, Barbara F. (ed.) (2000). Ethnologue. Vol. 1: Languages of the world. 14th edn. Dallas: SIL International.

Groot, A. W. de (1931). Phonologie und Phonetik als Funktionswissenschaften. Travaux du Cercle Linguistique de Prague 4. 116-147.

Groot, A. W. de (1948). Structural linguistics and phonetic law. Lingua 1. 175-208.

Reprinted from Archives Néerlandaises de Phonétique Expérimentale 17 (1941). 71-106.

Hall, T. Alan (1997). The phonology of coronals. Amsterdam: Benjamins.

Halle, Morris (1983). On distinctive features and their articulatory implementation. NLLT 1. 91-105. Reprinted in Halle (2002). 105-121.

Halle, Morris (1992). Phonological features. In William Bright (ed.) International encyclopedia of linguistics. Vol. 3. New York \& Oxford: Oxford University Press. 207-212.

Halle, Morris (2002). From memory to speech and back: papers on phonetics and phonology 1954-2002. Berlin \& New York: Mouton de Gruyter.

Halle, Morris \& Kenneth N. Stevens (1971). A note on laryngeal features. MIT Research Laboratory of Electronics Quarterly Progress Report 101. 198-212. Reprinted in Halle (2002). 45-61.

Hinskens, Frans \& Jeroen van de Weijer (2003). Patterns of segmental modification in consonant inventories: a cross-linguistic study. Linguistics 41. 1041-1084.

Hockett, Charles F. (1955). A manual of phonology. Baltimore: Waverly Press.

Howe, Darin \& Douglas Pulleyblank (2001). Patterns and timing of glottalisation. Phonology 18. 45-80.

Janson, Tore (1991). Comments on Maddieson: investigating linguistic universals. Proceedings of the 12th International Congress of Phonetic Sciences. Vol. 1. Aixen-Provence: Université de Provence. 355-358.

Kagaya, Ryohei \& Hajime Hirose (1975). Fiberoptic, electromyographic and acoustic analysis of Hindi stop consonants. Annual Bulletin of the Research Institute of Logopedics and Phoniatrics 9. 27-46.

Keating, Patricia A. (2003). Phonetic and other influences on voicing contrasts. In Solé et al. (2003). 375-378. 


\section{G. N. Clements}

Ladefoged, Peter (1968). A phonetic study of West African languages. 2nd edn. Cambridge: Cambridge University Press.

Ladefoged, Peter \& Ian Maddieson (1996). The sounds of the world's languages. Cambridge, Mass. \& Oxford: Blackwell.

Liljencrants, Johan \& Björn Lindblom (1972). Numerical simulation of vowel quality systems: the role of perceptual contrast. $L g$ 48. 839-862.

Lindblom, Björn (1986). Phonetic universals in vowel systems. In Ohala \& Jaeger (1986). 13-44.

Lindsey, Geoffrey, Katrina Hayward \& Andrew Haruna (1992). Hausa glottalic consonants: a laryngographic study. Bulletin of the School of Oriental and African Studies 55. 511-527.

Lombardi, Linda (1994). Laryngeal features and laryngeal neutralization. New York: Garland. $1991 \mathrm{PhD}$ dissertation, University of Massachusetts.

Louw, J. A. (1962). On the segmental phonemes of Zulu. Afrika und Übersee 46. 43-93.

McCarthy, John (1999). Distinctive features. In Robert A. Wilson \& Frank C. Keil (eds.) The MIT encyclopedia of the cognitive sciences. Cambridge, Mass. : MIT Press. $234-236$.

Maddieson, Ian (1984). Patterns of sounds. Cambridge: Cambridge University Press.

Maddieson, Ian (1991a). Testing the universality of phonological generalizations with a phonetically specified segment database: results and limitations. Phonetica 48. 193-206.

Maddieson, Ian (1991b). Investigating linguistic universals. Proceedings of the 12th International Congress of Phonetic Sciences. Vol. 1. Aix-en-Provence: Université de Provence. 346-354.

Maddieson, Ian (1995). Gestural economy. In Kjell Elenius \& Peter Branderud (eds.) Proceedings of the 13th International Congress of Phonetic Sciences. Vol. 4. Stockholm: KTH \& Stockholm University. 574-577.

Maddieson, Ian \& Karen Precoda (1989). Updating UPSID. UCLA Working Papers in Phonetics 74. 104-111.

Martinet, André (1952). Function, structure, and sound change. Word 8. 1-32.

Martinet, André (1955). Économie des changements phonétiques. Berne: Francke.

Martinet, André (1968). Phonetics and linguistic evolution. In Bertil Malmberg (ed.) Manual of phonetics. Completely revised and extended edition. Amsterdam: NorthHolland. 464 487. Reprinted from the 1st edition (1957), edited by L. Kaiser. $252-273$.

Mester, R. Armin \& Junko Itô (1989). Feature predictability and underspecification: palatal prosody in Japanese mimetics. $L g$ 65. 258-293.

Mous, Maarten (1993). A grammar of Iraqw. Hamburg: Buske.

Ohala, John J. (1980). Introduction to the symposium on phonetic universals in phonological systems and their explanation. In Proceedings of the 9th International Congress of Phonetic Sciences. Vol. 3. University of Copenhagen: Institute of Phonetics. 181-185.

Ohala, John J. \& Jeri J. Jaeger (eds.) (1986). Experimental phonology. Orlando: Academic Press.

Pandey, Pramod (2003). Sounds and their patterns in the languages of India. Part II : phonological sketches. Ms, Jawaharlal Nehru University.

Pinkerton, Sandra (1986). Quichean (Mayan) glottalized and nonglottalized stops: a phonetic study with implications for phonological universals. In Ohala \& Jaeger (1986). 125-139.

Pokharel, Madhav Prasad Sharma (1989). Experimental analysis of Nepali sound system. PhD dissertation, Deccan College, Pune.

Price, P. David (1976). Southern Nambiquara phonology. IFAL 42. 338-348. 
Sagey, Elizabeth (1990). The representation of features and relations in nonlinear phonology. New York: Garland. $1986 \mathrm{PhD}$ dissertation, MIT.

Schwartz, Jean-Luc, Louis-Jean Boë, Nathalie Valleee \& Christian Abry (1997). The Dispersion-Focalization Theory of vowel systems. FPh 25. 255-286.

Schuh, Russell G. \& Lawan D. Yalwa (1999). Hausa. In Handbook of the International Phonetic Association. Cambridge: Cambridge University Press. 90-95.

Simpson, Adrian P. (1999). Fundamental problems in comparative phonetics and phonology: does UPSID help to solve them? In John J. Ohala, Yoko Hasegawa, Manjari Ohala, Daniel Granville \& Ashlee C. Bailey (eds.) Proceedings of the 14th International Congress of Phonetic Sciences. Vol. 1. Berkeley: University of California. 349-352.

Solé, M. J., D. Recasens \& J. Romero (eds.) (2003). Proceedings of the 15th International Congress of Phonetic Sciences. Adelaide: Causal Productions.

Stevens, Kenneth N. (1983). Design features of speech sound systems. In Peter F. MacNeilage (ed.) The production of speech. New York: Springer. 247-261.

Stevens, Kenneth N. (1989). On the quantal nature of speech. $\mathscr{F P h ~ 1 7 . ~ 3 - 4 5 . ~}$

Tosco, Mauro (1991). A grammatical sketch of Dahalo. Hamburg: Buske.

Traill, A., J. S. M. Khumalo \& P. Fridjhon (1987). Depressing facts about Zulu. African Studies 46. 255-274.

Trubetzkoy, N. S. (2001). Studies in general linguistics and language structure. Edited and with an introduction by Anatoly Liberman. Durham: Duke University Press.

Um, Hye-Young (2001). Typology of glottalized sonorants: distributional patterns and phonetic explanations. Studies in Phonetics, Phonology and Morphology 7. 333-352.

Whiteley, W. H. (1958). A short description of item categories in Iraqw. Kampala: East African Institute of Social Research.

Williamson, Kay (1989). Niger-Congo overview. In John Bendor-Samuel (ed.) The Niger-Congo languages. Lenham, Md.: University Press of America. 3-45.

Wright, Richard, Sharon Hargus \& Katharine Davis (2002). On the categorization of ejectives: data from Witsuwit'en. Fournal of the International Phonetic Association 32. $43-77$. 